\title{
It Might Have Been: Risk, Precaution AND OPPORTUNITY COSTS
}

\author{
DOUGLAS A. KYSAR*
}

I. INTRODUCTION............................................. 1

II. THE PROBLEM OF UNCERTAINTY............................... 12

A. Complexity................................................ 14

B. Catastrophe............................................ 20

C. Procedural Rationality.................................... 23

III. The Problem of VAluation.................................. 28

A. Emergence.................................................. 30

B. Membership........................................... 33

C. Discursive Rationality................................. 39

IV. The Problem of AGEnCY.................................. 42

A. Partiality.................................................. 44

B. Collectivity ............................................ 48

C. Moral Rationality...................................... 52

V. CONCLUSION .............................................. 56

\section{INTRODUCTION}

In a 1959 lecture, the late physicist Richard Feynman famously observed that, in principle, nothing prevents "the possibility of [humans] maneuvering things atom by atom." 1 Today, the scientific field that Feynman foresaw-nanotechnology—not only exists, but receives over one billion dollars in federal funding per year for

\footnotetext{
* Professor of Law, Cornell Law School. This research was supported, in part, by the National Science Foundation's Nanotechnology and Interdisciplinary Research Award \#0304483. In writing this Article, I have benefited from comments and suggestions from far too many individuals to enumerate. Special thanks, however, are owed to Matt Adler, Bill Alford, Bruce Ackerman, Susan Rose Ackerman, Sam Bagenstos, Don Braman, Jules Coleman, Bill Eskridge, Dan Esty, Ryan Goodman, Buzz Holling, Dan Kahan, Daniel Markovits, Jerry Mashaw, Bernadette Meyler, Marc Miller, Trevor Morrison, J.B. Ruhl, Margo Schlanger, Joanne Scott, Seana Shiffrin, Kenneth Simons, Mark Tushnet, and David Walker. At various stages in this Article's development, I have also received helpful feedback through presentations at the University of Arizona Rogers College of Law, the Boston University School of Law Law and Economics Workshop, the University of California-Los Angeles School of Law Legal Theory Workshop, the Florida State University College of Law, the Georgetown University Law Center Workshop on Governance, the Harvard Law School International Law Workshop, the Midwestern Law and Economics Association Annual Meeting, the University of Minnesota Consortium on Law and Values in Health, Environment \& the Life Sciences, the Notre Dame Law School, the University of Pennsylvania Law School, the Stanford Law School, the Washington University School of Law, and the Yale Law School.
}

1. Richard P. Feynman, There's Plenty of Room at the Bottom, ENG. \& SCI. (1960). 
research in fields as varied as mechanical and electrical engineering, biology, medicine, information technology, optics, and cognitive science. ${ }^{2}$ Speculation by popular commentators about what this research ultimately will mean for humanity ranges from a utopian vision of boundless energy and zero pollution to a "gray goo" nightmare of self-replicating nanodevices that cause incomprehensibly vast material destruction. ${ }^{3}$

Even among expert observers, opinions of nanotechnology vary widely in their tone and content. A committee convened by the U.S. National Research Council, for instance, breathlessly predicted that "[w]ith potential applications in virtually every existing industry and new applications yet to be discovered, nanoscale science and technology will no doubt emerge as one of the major drivers of economic growth in the first part of the new millennium." 4 In contrast, given the dearth of knowledge presently available regarding human health and environmental consequences of nanomaterials, a report issued in Britain by The Royal Society and The Royal Academy of Engineering recommended "as a precautionary measure that factories and research laboratories treat manufactured nanoparticles and nanotubes as if they were hazardous." 5

Although it would be easy to overstate the distinction between U.S. and European approaches to risk regulation, ${ }^{6}$ it is neverthe-

2. The 21st Century Nanotechnology Research and Development Act, passed in 2003, allocates nearly $\$ 3.7$ billion to nanotechnology research from 2005 to 2008 , not including substantial expenditures on defense related nanoscale research.

3. Compare Lynn. L. Bergeson \& Bethami Auerbach, 21 ENVTL. ForUM 30, 32 (March/April 2004) (calling nanotechnology "perhaps the ultimate sustainable development tool") and Gary Stix, Little Big Science, SCI. AMERICAN 32, 37, Sept. 16, 2001 ("If the nano concept holds together, it could, in fact, lay the groundwork for a new industrial revolution."), with Bill Joy, Why the Future Doesn't Need Us, WIRED, August 4, 2000, available at http://www.wired.com/wired/archive/8.04/joy_pr.html (discussing the "gray goo" problem and asserting that "[o]ur most powerful 21st-century technologies - robotics, genetic engineering, and nanotech - are threatening to make humans an endangered species."). See also Glenn Harlan Reynolds, Environmental Regulation of Nanotechnology, 31 ENVTL. L. REP. 10681, 10681 (2001) (noting that predictions of the environmental implications of nanotechnology range from "the most radical of the green visions" to the "worry that rogue nanodevices will devour the planet").

4. Committee For the Review of the National Nanotechnology Initiative, DiviSion on EngineERING and Physical Sciences, National RESEARCh Council, SMall Wonders, Endless Frontiers: A Review of the National NANotechnology INitiative 2 (2002).

5. See, e.g., The Royal Society AND The Royal ACADEMy OF Engineering, NANOSCIENCE AND NANOTECHNOLOGIES: OpPoRTUNITIES AND UnCERTAINTIES, Summary 5 (July 2004).

6. As Jonathan Wiener has noted, the common perception that the United States tends to favor more permissive policies than the European Union overlooks important exceptions and nuances-witness, for instance, the stronger European embrace of nuclear power or the greater U.S. willingness to deter public smoking. See Jonathan B. Wiener, Whose Precaution After All? A Comment on the Comparison and Evolution of Risk Regulatory Systems, 13 DukE J. ComP. \& INT'L L. 207, 229 (2003). See also Jonathan B. Wiener \& Michael D. Rogers, Comparing Precaution in the United States and Europe, 5 J. RISK RES. 
less striking how the reports of these respective national agencies appear to reinforce the common perception that U.S. experts and policymakers today favor less conservative environmental, health, and safety measures than their European counterparts. The British scientific societies, for instance, called for a national prohibition on "the use of free nanoparticles in environmental applications such as remediation of groundwater," pending development of better scientific information and understanding regarding the potential consequences of such releases. Researchers in the United States, on the other hand, already are engaging in field releases of nanoparticles in hopes of uncovering substances capable of remediating pollution. ${ }^{8}$ Similarly, a European Union scientific committee carefully scrutinized the health risks of sunscreen products that contain free nanoparticles, ultimately refusing to approve microfine zinc oxide for use as a UV filter in light of suggestive evidence that the substance might pass through the skin and damage DNA. ${ }^{9}$ During the U.S. Food and Drug Administration (FDA)'s review of nanoparticle-containing sunscreens, on the other hand, the agency confidently opined that chemical substances shown to be safe at the macroscale also can be assumed, without further investigation, to be safe at the nanoscale. ${ }^{10}$

This apparent difference in regulatory attitude between the United States and Europe often is said to emerge from the jurisdictions' contrasting stances toward two policymaking paradigms that compete for acceptance within environmental, health, and safety regulation: One-known as cost-benefit analysis (CBA) and increasingly associated with the United States ${ }^{11}$ — strives to enhance social welfare by predicting, weighting, and aggregating all relevant consequences of policy proposals in order to identify those

317 (2002). Such ready counterexamples notwithstanding, there remains an important sense in which U.S. and European policymakers believe themselves to be engaged in a debate over appropriate regulatory approaches going forward. See, e.g., ARIE TrouwBonst, EVOlution AND Status OF THE PRECAUTIONARY PRINCIPLE IN INTERNATIONAL LAW 82 (2002) (describing U.S.-led opposition to inclusion of the PP in the international convention on persistent organic pollutants on the basis that the principle was "unscientific"); id. at 138 (describing U.S. opposition to reliance on the PP within a report on risk analysis principles and guidelines at the Codex Alimentarius Commission). Explicating the theoretical and practical differences of these approaches therefore remains a significant exercise, regardless of how closely U.S. and European regulations and attitudes in the past conform to the common stereotype.

7. The Royal Society AND The Royal ACADEMY of EngIneERING, supra note 5, at 5 .

8. See Wei-Xian Zhang, Nanoscale Iron Particles for Environmental Remediation: An Overview, 5 J. NANOPARTICLE RES. 323, 32 (2003).

9. See SCCNFP, Opinion Concerning Zinc Oxide (Colipa nS76). SCCNFP/0690/03, available at http://ec.europa.eu/health/ph_risk/committees/sccp/documents/out222_en.pdf.

10. See FDA, 64 Fed. Reg. 27666, 27671 (1999).

11. See Cass R. Sunstein, The Cost-Benefit State ix (2002) ("Gradually, and in fits and starts, American government is becoming a cost-benefit state.") [hereinafter SUNSTEIN, THE COST-BEnEFIT STATE]. 
choices that represent welfare-maximizing uses of public resources; the other-associated with the precautionary principle (PP) and the European approach to risk regulation ${ }^{12}$ - eschews optimization in favor of more pragmatic forms of decisionmaking. One oft-cited articulation of the PP, for instance, seeks to trigger an incremental process of risk regulation through the simple admonition, "When an activity raises threats of harm to human health or the environment, precautionary measures should be taken even if some cause and effect relationships are not fully established scientifically." 13

Despite the efforts of numerous scholars to forge a middle path between these extremes of "comprehensive rationality and

12. See, e.g., Treaty on European Union, Official Journal C 191, 29 July 1992, at art. 130r(2) (stating that EC environmental policy "shall be based on the precautionary principle"); Commission of the European Community, Communication from the Commission on the Precautionary Principle, February 2, 2000, available at http://europa.eu.int/comm/ dgs/health_consumer/library/pub/pub07_en.pdf. See also Robert W. Hahn \& Cass R. Sunstein, The Precautionary Principle as a Basis for Decisionmaking, The Economist's Voice, Vol. 2, No. 2, Article 8 (2005) [hereinafter Hahn \& Sunstein, Basis for Decisionmaking] (noting that "[t]he European Union has taken a leadership role in promoting the precautionary principle as a basis for making decisions on environmental policy and other areas"); Cass R. Sunstein, Precautions Against What? The Availability Heuristic and Cross-Cultural Risk Perceptions 1-2 (Univ. Chicago John M. Olin Law \& Econ. Working Paper No. 220, 2d Series, 2004) [hereinafter Sunstein, Precautions Against What?] (observing that "[i]t has become standard to say that with respect to risks, Europe and the United States can be distinguished along a single axis: Europe accepts the Precautionary Principle, and the United States does not"); Gail Charnley \& E. Donald Elliott, Democratization of Risk Analysis, in Human and Ecological Risk Assessment: Theory and Practice 1399, 1401 (Dennis J. Paustenbach ed., 2002) ("When Europeans call for decisions based on "the precautionary principle' in international forums, they are challenging the core premise of the American legal culture.").

13. Peter Montague, The Precautionary Principle, Rachel's EnV'T \& HEAlth WKLY., Feb. 18, 1998, at 1, available at http://www.rachel.org/bulletin/bulletin.cfm? Issue_ID=532 (describing and quoting the 1998 Wingspread Declaration). See also 1991 Convention on the Ban of Import into Africa and the Control of Transboundary Movement and Management of Hazardous Wastes Within Africa, art. 3(f), available at www.ban.org/library/bamako _treaty.html (requiring implementation of "the precautionary principle to pollution prevention through the application of clean production methods, rather than the pursuit of a permissible emissions approach based on assimilative capacity assumptions"). Other formulations of the PP do not contain an affirmative requirement to undertake precautionary measures. Instead, they simply state that scientific uncertainty by itself should not be taken to weigh against the adoption of precautionary measures. See, e.g., United Nations Conference on Environment and Development: Convention on Biological Diversity, prmbl., 31 I.L.M. 818, 822 (1992) (declaring that "where there is a threat of significant reduction or loss of biological diversity, lack of full scientific certainty should not be used as a reason for postponing measures to avoid or minimize such a threat"). It is sometimes argued that this interpretation of the PP is a mere 'truism' that should be uncontroversial. Proponents of this version of the principle, however, offer their seemingly trivial reminder in response to "the self-interested claims of private groups demanding unambiguous evidence of harm" before environmental, health, and safety regulations are imposed. Cass R. Sunstein, Beyond the Precautionary Principle, 151 U. PA. L. REV. 1003, 1016 (2003). Such claims have proven surprisingly successful in many policy debates (including especially the U.S. climate change debate), despite the fact that "no rational society requires" full certainty before acting. $I d$. at 1016-17. 
incrementalism,"14 today the debate over CBA and the PP in the environmental, health, and safety context remains as polarized as ever. On the one hand, several influential commentatorsincluding Matthew Adler and Eric Posner, ${ }^{15}$ Kenneth Arrow, ${ }^{16}$ Justice Stephen Breyer, ${ }^{17}$ Judge Richard Posner, ${ }^{18}$ Cass Sunstein, ${ }^{19}$ and others ${ }^{20}$ - have come to the conclusion that the normative case in favor of CBA is simply overwhelming and that competing paradigms such as the $\mathrm{PP}$ are either incoherent or inappropriate as frameworks for risk regulation. The conclusion of these thinkers is particularly notable in light of their acknowledgment that CBA suffers from a number of conceptual and practical limitations of its own. Nevertheless, CBA's proponents increasingly believe that the "first generation debate" about the procedure's normative desirability is over and that today the important questions concern "second generation" issues of how best to implement CBA in the environmental, health, and safety regulation context. ${ }^{21}$ The basic

14. Colin S. Diver, Policymaking Paradigms in Administrative Law, 95 HaRv. L. REv. 393, 395 (1981). For examples of scholarship aiming to bridge the divide between the PP and CBA, see DAniel A. FARBer, Eco-Pragmatism: Making Sensible Environmental DECISIONS IN AN UNCERTAIN WORLD (1999); J. B. Ruhl, A Manifesto for the Radical Middle, 38 IDAHO L. REV. 385, 385-86 (2002); J. B. Ruhl, Working Both (Positivist) Ends Toward a New (Pragmatist) Middle in Environmental Law, 68 GEO. WASH. L. REV. 522, 524 (2000) (reviewing Daniel A. FARBer, Ecopragmatism: MAKing Sensible Environmental DeciSIONS IN AN UNCERTAIN WORLD (1999)); Symposium, The Pragmatic Ecologist: Environmental Protection as a Jurisdynamic Experience, 87 MINN. L. REV. 847 (2003).

15. See Matthew D. Adler \& Eric A. Posner, Rethinking Cost-Benefit Analysis, 109 YALE L. J. 165 (1999).

16. See Kenneth J. Arrow et al., Is There a Role for Benefit-Cost Analysis in Environmental, Health, and Safety Regulation?, 272 SCIENCE 221 (1996); Kenneth J. Arrow \& Robert C. Lind, Uncertainty and the Evaluation of Public Investment Decisions, 60 AM. ECON. REV. 364, 366-67 (1970).

17. Stephen Breyer, Breaking the Vicious Circle: Toward Effective Risk ReguLATION (1993).

18. Richard A. Posner, CATASTROPhe: Risk AND Response (2004) [hereinafter, Posner, Catastrophe]; Richard A. Posner, Cost-Benefit Analysis: Definition, Justification, and Comment on Conference Papers, 29 J. LEGAL STUD. 1153 (2000).

19. See Sunstein, The Cost-Benefit State, supra note 11; Cass R. Sunstein, Laws of Fear: Beyond the Precautionary Principle (2005) [hereinafter Sunstein, LaWs of Fear]; Cass R. Sunstein, Risk \& REAson: SAFEty, LaW, and the EnVironment (2002) [hereinafter SUnsteIn, RISK \& REASON]; Sunstein, Beyond the Precautionary Principle, supra note 13; Cass R. Sunstein, Cognition and Cost-Benefit Analysis, 29 J. LEGAL STUD. 1059 (2000); Cass R. Sunstein, Cost-Benefit Default Principles, 99 Mich. L. REv. 1651 (2001).

20. See, e.g., Mark Geistfeld, Reconciling Cost-Benefit Analysis With the Principle That Safety Matters More Than Money, 76 N.Y.U. L. REV. 114 (2001); Robert H. Frank, Why Is Cost-Benefit Analysis So Controversial?, 29 J. LEGAL STUD. 913 (2000); W. Kip Viscusi, Regulating the Regulators, 63 U. CHI. L. REV. 1423 (1996).

21. Sunstein, The Cost-Benefit State, supra note 11, at xi. See also Sunstein, Risk \& REASON, supra note 19, at 5-6 (asserting that "first-generation' debate about whether to base regulatory choices on cost-benefit analysis at all. . . is now ending, with a substantial victory for the proponents of cost-benefit analysis"); Hahn \& Sunstein, Basis for Decisionmaking, supra note 12, at 6 ("We do not believe there is any principled way of making policy 
superiority of CBA as a policy tool for risk regulation, in other words, is no longer seriously doubted.

Except, of course, that it is, and not just by the "environmental Darth Vader[s]" of the world, ${ }^{22}$ but by serious, thoughtful observers of the administrative state. ${ }^{23}$ For instance, Frank Ackerman and Lisa Heinzerling maintain that regulatory CBA as commonly practiced is flawed for at least four critical reasons: "[T] he standard economic approaches to valuation are inaccurate and implausible; the use of discounting [to compare intertemporal costs and benefits] improperly trivializes future harms and the irreversibility of some environmental problems; the reliance [of CBA] on aggregate, monetized benefits excludes questions of fairness and morality; and the value-laden and complex cost-benefit process is neither objective nor transparent." 24 Moreover, the response of some CBA proponents to call for a "modest, nonsectarian" 25 brand of cost-benefit calculation in light of these arguable shortcomings does not satisfy thinkers such as Ackerman and Heinzerling. In their view, CBA's flaws render the procedure irredeemable as a device for setting standards of environmental, health, and safety protection. ${ }^{26}$ Accordingly, they applaud the fact the precautionary approach continues to enjoy more prominence and support than CBA outside of U.S. academic and policy cir-

decisions without making the best possible effort to balance all the relevant costs of a policy against the benefits.").

22. Alex Kozinski, Gore Wars, 100 MicH. L. REV. 1742, 1767 (2002) (reviewing BJøRN Lomborg, The Skeptical Environmentalist: Measuring The Real State Of The WORLD (2001)).

23. See, e.g., Frank Ackerman \& Lisa Heinzerling, Priceless: On Knowing the Price of Everything AND the Value of Nothing (2004) [hereinafter Ackerman \& Heinzerling, Priceless]; Sidney A. Shapiro \& Robert L. Glicksman, Risk Regulation At Risk: Restoring a Pragmatic ApProAch (2003); David M. Driesen, The Societal Cost of Environmental Regulation: Beyond Administrative Cost-Benefit Analysis, 24 ECOLOGY L.Q. 545 (1997); Gregory C. Keating, Pressing Precaution Beyond the Point of Cost-Justification, 56 VAND. L. REV. 653 (2003); Gregory C. Keating, Pricelessness and Life: An Essay for Guido Calabresi, 64 MD. L. REV. 159 (2005); Thomas O. McGarity, A Cost-Benefit State, 50 ADMIN. L. REV. 7 (1998); Thomas O. McGarity, The Goals of Environmental Legislation, 31 B.C. ENVTL. AFF. L. REV. 529 (2004) [hereinafter McGarity, Goals]; Thomas O. McGarity, MTBE: A Precautionary Tale, 28 HARV. ENVTL. L. REV. 281 (2004) [hereinafter, McGarity, MTBE]; Thomas O. McGarity \& Ruth Ruttenberg, Counting the Cost of Health, Safety, and Environmental Regulation, 80 TEX. L. REV. 1997 (2002); Amy Sinden, Cass Sunstein's CostBenefit Lite: Economics for Liberals, 29 CoLUM. J. ENVTL. L. 191 (2004).

24. Frank Ackerman \& Lisa Heinzerling, Pricing the Priceless: Cost-Benefit Analysis of Environmental Protection, 150 U. PA. L. REV. 1553, 1563 (2002).

25. Robert W. Hahn \& Cass R. Sunstein, A New Executive Order for Improving Federal Regulation? Deeper and Wider Cost-Benefit Analysis 7 (Univ. Chicago-John M. Olin Law \& Econ. Working Paper No. 150, 2002).

26. See ACKERMAN \& HEINZERLING, PRICELESS, supra note 23, at 219-220 (arguing that "the most fundamental problem is not in the details of any particular cost-benefit analysis, but rather in the framing decision about which policies are and which are not subject to such analyses"). 
cles $^{27}$ - a fact that critics instead want to attribute to such failings as poor information, ${ }^{28}$ cognitive error, ${ }^{29}$ and public hysteria. ${ }^{30}$

This Article, which is part of a larger project on the competing merits of CBA and the PP, ${ }^{31}$ examines one specific plank of the case against the PP: the claim that the principle's ignorance of the opportunity costs of precaution leads to indeterminate or impoverishing policy advice. Because PP defenders emphasize the limits of human knowledge and the frequency of unpleasant surprises from technology and industrial development, they prefer an ex ante stance of precaution whenever a proposed activity meets some threshold possibility of causing severe harm to human health or the environment. ${ }^{32}$ Importantly, they prefer this stance even in the face of potential benefits-such as those promised by the use of nanoparticles in groundwater remediation or skin protection-that may themselves be ameliorative of environmental, health, and safety dangers. Although their reasoning has never been perfectly

27. In addition to its expression in European Union law and in the domestic laws and regulations of many nations outside of the E.U., see Treaty on European Union, supra note 12 , the PP also has appeared in a number of multilateral documents and is even considered by some observers to be a strong candidate for inclusion within customary international law. See Nuclear Tests (N.Z. v. Fr.), 1995 I.C.J. 288 (Sept. 22) 342 (Weeramantry, J., dissenting) (noting that the PP is "gaining increasing support as part of the international law of the environment"); id. at 412 (Palmer, J., dissenting) (observing that "the norm involved in the precautionary principle has developed rapidly and may now be a principle of customary international law relating to the environment."); Gabcikovo-Nagymaros Project (Hung. v. Slovk.), 1997 I.C.J. 7 (Sept. 25). See also F. ORREGA Vicuña, The Changing InTERnATIONAL LAW OF HIGH SEAS FISHERIES 156 (1999) ("The precautionary principle . . . has taken a central place in the discussion of most international regimes for environmental protection."); David Freestone \& Ellen Hey, Origins and Development of the Precautionary Principle, in The Precautionary Principle and International LaW: The Challenge of ImPLEMENTATION 3, 3 (David Freestone \& Ellen Hey eds., 1996) (“[T]he precautionary concept has been included in virtually every recent treaty and policy document related to the protection and preservation of the environment.").

28. See Aaron Wildavsky, But is it True?: A Citizen's Guide to Environmental HEALTH AND SAFETY ISSUES 1-2 (1995).

29. See Sunstein, Risk AND REASON, supra note 19, at 28-52.

30. See Tumur Kuran \& Cass R. Sunstein, Availability Cascades and Risk Regulation, 51 STAN. L. REV. 683 (1999) (positing that rational risk regulation is confounded by the political pressure exerted by "populist firestorms").

31. See Douglas A. Kysar, The Point of Precaution: Economics, the PrecautionARY PRINCIPLE, AND OUR ENVIRONMENTAL FUTURE (working title for unpublished manuscript, on file with author).

32. The statement in the text captures the essential structure of the PP. See, e.g., TROUWBORST, supra note 6, at 52 ("[I]n the presence of a threat of (non-negligible) environmental harm accompanied by scientific uncertainty, regulatory action should nevertheless be taken to prevent or remedy the hazard concerned.") (emphasis omitted). Important implementation issues then include: (1) the degree of credibility or seriousness of threat required in order to trigger the precautionary obligation; (2) the precise form that regulatory response should take; (3) and the manner in which the regulatory response should be revisited and revised over time. See John S. Applegate, The Taming of the Precautionary Principle, 27 WM. \& MARY ENVTL. L. \& POL’Y REV. 13 (2002) [hereinafter Applegate, Taming]. 
clear, ${ }^{33}$ advocates of the PP regard such foregone benefits as conceptually distinct from, and somehow less central than, the more affirmative consequences that may result from allowing potentially harmful activities to proceed.

Naturally, this asymmetric aspect of the PP generates strident criticism, particularly from consequentialist-utilitarian thinkers such as those who advocate CBA. Along with substitute risks, lulling effects, and other purportedly overlooked health consequences of precautionary regulation, ${ }^{34}$ these critics argue that the PP's failure to treat opportunity costs pari passu with the primary risks targeted by policy measures is simply indefensible. Moreover, they argue that if opportunity costs of regulation were taken into account in the design of the PP, then "the real problem with the principle [would become] that it offers no guidance-not that it is wrong, but that it forbids all courses of action, including regulation." 35 To the PP's detractors, therefore, the principle either

33. The classic defense of the PP contends that the benefits of regulatory precaution consist of saved human lives or averted ecological harms, while the costs typically consist of lost economic profits or some other opportunity cost that is not viewed as fully commensurable with human or environmental harm. See Talbot Page, A Generic View of Toxic Chemicals and Similar Risks, 7 Ecology L.Q. 207, 22 (1978); Sidney A. Shapiro, Keeping the Baby and Throwing Out the Bathwater: Justice Breyer's Critique of Regulation, 8 ADMIN. L.J. AM. U. 721, 732 (1995); Kristin Shrader-Frechette, Methodological Rules for Four Classes of Scientific Uncertainty, in SCIENTIFIC UNCERTAINTY AND ENVIRONMENTAL PROBLEM SOLVING 12, 14-15 (John Lemons, ed.) (1995). As noted infra text accompanying notes 50-58, this incommensurability defense is partially (but only partially) undermined by the frequent appearance of human lives or ecological assets on both sides of the regulatory ledger.

34. For an influential analytical overview and collection of case studies involving such "risk-risk" tradeoffs, see JOHN D. GRAHAM \& JONATHAN BAERT WIENER, RISK VERSUS RISK (1995).

35. Sunstein, Precautions Against What?, supra note 12, at 7. See also M. GoKLANY, The Precautionary Principle: A Critical ApPraisal of EnVIRONMENTAl Risk AssessMENT (2001); Howard MARgolis, DEALING With Risk: Why the PUbliC AND THE EXPERTS DISAGREE ON ENVIRONMENTAL ISSUES 2 (1996) ("Good judgment-judgment that will look reasonable when the passions of the moment have passed-has to deal with what I label the 'fungibility' (between opportunities and dangers) that ordinarily confronts us."); SUNSTEIN, LAWS OF FEAR, supra note 19, at 42 (observing that precautionary risk regulation tends to lack "concern[] [for] the benefits that are foregone as a result of regulation"); Jonathan B. Wiener, Precaution in a Multi-Risk World, in HUMAN AND ECOLOGICAL RISK AsSESSMENT: Theory AND PRACTICE 1509 (Dennis D. Paustenbach ed., 2002); Jonathan H. Adler, More Sorry Than Safe: Assessing the Precautionary Principle and the Proposed International Safety Protocol, 35 TEX. INT'L L. J. 173, 195 (2000) (“The problem is that by focusing on one set of risks - those posed by the introduction of new technologies with somewhat uncertain effects - the precautionary principle turns a blind eye to the harms that occur, or are made worse, due to the lack of technological development."); Frank B. Cross, Paradoxical Perils of the Precautionary Principle, 53 WASH. \& LEE L. REV. 851 (1996); Howard Margolis, A New Account of Expert/Lay Conflicts of Risk Intuition, 8 DuKE ENVTL. L. \& POL’Y F. 115 (1997); John O. McGinnis, The Appropriate Hierarchy of Global Multilateralism and Customary International Law: The Example of the WTO, 44 VA. J. INT'L L. 229, 273 (2003) (arguing that "the precautionary principle often remains coherent only by focusing on the risks of action at the expense of those of inaction"); Christopher D. Stone, Is There a Precautionary Principle?, 31 ENVTL. L. REP. 10790 (2001); Cass R. Sunstein, Cost-Benefit Analysis and the Environment, 18 (Univ. Chicago-John M. Olin Law \& Econ. Working Paper No. 227, 2d series, 
must be expanded to include an obligation to consider the opportunity costs of regulatory activity-in which case it would become woefully indeterminate - or the principle must be rejected as a one-sided tool that is likely to prolong a range of harms that would be alleviated in its absence.

Despite the seemingly unimpeachable logic of this critique, the role of opportunity costs in environmental, health, and safety regulation actually turns out to be much more complicated and interesting than the CBA proponents' account reveals. Undoubtedly, CBA proponents are correct to note that no society should flatly ignore the opportunity costs of precautionary regulation. But this is a trivial observation, for no serious proponent of the PP disagrees with it. Despite frequent caricature of the PP as a crudely asymmetric heuristic, ${ }^{36} \mathrm{PP}$ proponents actually regard the principle as merely one aspect of a much more elaborate regulatory process in which the PP is applied with a view toward proportionality of response ${ }^{37}$ and adaptability over time. ${ }^{38}$ Just as no physician would unthinkingly and universally follow the precautionary mandate of the Hippocratic adage- "first, do no harm"-no regulator would adhere to the PP without paying some attention to foregone benefits, new information, and changed circumstances. ${ }^{39}$ Thus, the proper contrast between CBA and the $\mathrm{PP}$ is not one of comprehensive and partial modes of analysis, as critics of the $\mathrm{PP}$ assert, ${ }^{40}$ but

2004) available at http://www.law.uchicago.edu/lawecon/index.html (arguing that "[w]hen the principle seems to give guidance, it is often because those who use it are focusing on one aspect of risk-related situations and neglecting others."); Cass R. Sunstein \& Adrian Vermeule, Is Capital Punishment Morally Required? The Relevance of Life-Life Tradeoffs, (Univ. Chicago John M. Olin Law \& Econ. Working Paper No. 239, 2005) available at http://ssrn.com/abstract_id=691447 [hereinafter Sunstein \& Vermeule, Capital Punishment] ("No one believes that for moral reasons, social planners should refuse to take account of [risk-risk] tradeoffs.") (subsequently published as Cass R. Sunstein \& Adrian Vermeule, Is Capital Punishment Morally Required? Acts, Omissions, and Life-Life Tradeoffs, 58 STAN. L. REV. 703 (2005)).

36. See Applegate, Taming, supra note 32, at 29 ("Critics of the [PP] often misrepresent its regulatory standard as unitary and draconian: to ban or forgo an activity or technology altogether. Neither the texts of the [PP] nor the writings of its advocates bears this out.").

37. See Commission of the European Communities, Communication from the Commission on the precautionary principle, COM (2000) 1 (Feb. 2, 2000) (emphasis added) [hereinafter Communication from the Commission], available at http://europa/eu/int/comm/dgs/ health_consumer/library/pub/pub07_en.pdf.

38. See Joanne Scott, The Precautionary Principle Before the European Courts, in PRINCIPLES OF EUROPEAN ENVIRONMENTAL LAW 51, 62, 64 (Richard Macrory et al. eds., 2004) (observing that the PP is applied in a conditional, preliminary fashion that not only allows decisionmakers to "exercise their judgment with respect to risk," but also helps to avoid the possibility that the PP "will threaten paralysis in the manner feared by [critics of the principle]").

39. See id.; Communication from the Commission, supra, note 37; infra text accompanying notes 161-163 (describing various "safety valves" associated with the precautionary approach that allow for relaxation of its dictates in appropriate circumstances).

40. See supra note 34 . 
rather of static and dynamic, optimizing and incremental, formalized and pragmatic decisionmaking models.

As Parts I and II of this Article demonstrate, there are underappreciated benefits to the PP's more modest approach. Specifically, unlike the optimization framework of CBA, which proceeds awkwardly in the absence of fully characterized risks and consensus normative agreement on exogenized choice criteria, the PP's approach reflects great sensitivity to the fact that decisionmaking in the face of many environmental problems demands not only substantive, but also procedural and discursive rationality. This is particularly the case with regard to the kinds of multidimensional, long-term questions that are raised by the paradigm of sustainable development law, ${ }^{41}$ and that reveal cost-benefit optimization to be both analytically and democratically unsatisfactory. Thus, Parts I and II conclude that the most important task presently facing scholars of environmental law is not, as CBA proponents would have it, to further refine the technical details of the optimization paradigm in order to suit the sustainable development challenge. Rather, the task is to reconcile environmental management's need for flexibility and dynamism with democracy's need for meaningful public input. The PP by itself does not resolve such challenges. However, significantly - and in contrast to CBA-it does acknowledge their existence and importance.

Although the critique of CBA offered in Parts I and II is aggressive, the aim is not to persuade readers of the force of any par-

41. See Douglas A. Kysar, Sustainable Development and Private Global Governance, 83 Texas L. Rev. 2109 (2005) [hereinafter Kysar, Sustainable Development]. The PP tends to be closely associated with the sustainable development movement. See U.N. Econ. Comm. for Eur. [UN/ECE], Bergen Ministerial Declaration on Sustainable Development in the ECE Region, I 7, U.N. Doc.A/Conf.151/PC/10 (May 16, 1990) ("In order to achieve sustainable development, policies must be based on the precautionary principle.”); James Cameron, The Precautionary Principle, in Trade, EnVIRONMENT, AND THE MilleniUm 239, 287-88 (Gary P. Sampson and W. Bradnee Chambers eds., 2002) ("The precautionary principle is part of a system of rules designed to guide human behavior towards the ideal of an environmentally sustainable economy."); Tim O'Riordan, Andrew Jordan, \& James Cameron, The Evolution of the Precautionary Principle, in ReInterpreting the Precautionary PRINCIPLe 9, 13 (Tim O'Riordan, James Cameron, \& Andrew Jordan eds., 2001) (noting that the PP's "future lies in the debate and policy setting of sustainability, rather than environmentalism"); Michael C. Farmer \& Alan Randall, The Rationality of a Safe Minimum Standard, 74 LAND ECON. 287, 287 (1998) (noting that some "advocates of the precautionary principle expand [safe minimum standard] protections into a comprehensive, strong sustainability objective"); J.B. Ruhl, Sustainable Development: A Five-Dimensional Algorithm for Environmental Law 18 Stan. EnVTL. L. J. 31 (1999) [hereinafter Ruhl, Sustainable Development]. Like the PP, the sustainable development concept has been harshly criticized as indeterminate and potentially counterproductive. See, e.g., Wilfred BECKERMAN, A Poverty of REASON: SusTAINABLE DEVElOPMENT AND ECONOMiC GROWTH (2002). Nevertheless, also like the PP, it has remained prominent and influential, particularly outside of the United States. See James Gustave Speth, International Environmental Law: Can It Deal With the Big Issues?, 28 VT. L. REV. 779, 790 (2004). 
ticular attack or even of the attacks in combination. Rather, the aim is to unsettle the view that the "first generation debate" in risk regulation has been unequivocally resolved in favor of CBA. ${ }^{42}$ Raising doubts in this manner serves to lend urgency to the more fundamental argument that is offered in Part III-the argument that CBA's most worrisome aspect is not the results that it generates in particular policy cases, but the threat that it poses over time to our ability even to continue debating how we might better manage environmental risk and achieve sustainable development. By its nature, CBA tends to suggest that government policies are "hostage to what the facts turn out to show in particular domains," 43 such that no distinctive notion of collective discretion and responsibility is deemed necessary or appropriate in the fashioning of public policy. So conceived, however, the methodology is unable in the end to account for the normativity of what the facts tell usthat is, for the assumption that some agent somewhere should act in accordance with the facts so discovered. ${ }^{44}$ In the long run, such an approach not only may prove disruptive to the project of reasoning through daunting moral issues, such as international and intergenerational environmental responsibility, that are not typically addressed by the CBA framework, but the approach also may undermine even its own attractiveness as a standard of social choice.

In strong terms, critics have attempted to dismiss the PP as "incoherent," 45 "indeterminate," 46 "paralyzing," 47 "worse than unhelpful," 48 and "literally senseless." 49 Their critiques, however, have overlooked the most desirable feature of the PP, which is not necessarily the level of environmental, health, and safety harm that it promises to avoid, but rather the more subtle manner in which the principle reflects and reinforces a notion of political communities as distinct entities with special responsibility to evaluate their decisions and actions in the context of other societies and other human generations. Despite its seemingly unequivocal command, the Hippocratic principle-"first, do no

42. See supra text accompanying note 21 .

43. Sunstein \& Vermeule, Capital Punishment, supra note 35, at 30.

44. $C f$. SAmuel SchefFler, Boundaries AND Allegiances: Problems of Justice AND RESPONSIBILITY IN LIBERAL THOUGHT 158 (2001) (observing that utilitarians must offer a "plausible and detailed account of utilitarian social and economic institutions and of the processes by which, in a society regulated by utilitarian principles, motives would develop that were capable of generating ongoing support for those institutions and principles").

45. Todd J. Zywicki, Baptists?: The Political Economy of Environmental Interest Groups, 53 CASE WES. L. REV. 315, 333 (2002).

46. Stone, supra note 35 , at 10799.

47. Sunstein, Beyond the Precautionary Principle, supra note 13, at 1004.

48. Cass R. Sunstein, Your Money or Your Life, NEw RePUBLIC, March 11, 2004.

49. Sunstein, Beyond the Precautionary Principle, supra note 13, at 1008. 
harm"-is not only or even primarily a behavioral prescription. It is instead a subtle, but steadfast reminder to the professional so cautioned that her actions carry distinctive moral weight and responsibility. It is a reminder most fundamentally to be moral. Similarly, the PP's requirement that we pause to consider the potentially catastrophic or irreversible consequences of our action is at bottom a reminder that social choices express a collective moral identity. Our identity. An identity that cannot be located within the freestanding optimization logic of CBA, although we need to consider its content more now than perhaps ever before.

\section{THE PROBLEM OF UNCERTAINTY}

Every decision to act or refrain from acting implies a range of alternatives that, for better or worse, are not selected. For poets, it is these foregone options that constitute the "saddest" category of human thought and experience: what "might have been." 50 Likewise, for critics of the PP, it is primarily these counterfactual costs of behaving according to the principle's dictates that render the device so objectionable as a basis for public policymaking. The threat of genetically modified "super weeds" 51 looms large, as do the threats of catastrophic climate change ${ }^{52}$ and runaway nanodevices that transform the planet into "gray goo." 53 Less visible, and therefore less attended to according to proponents of the synoptic paradigm, are the vitamin enriched rice strains, ${ }^{54}$ the carbon fueled economic gains, ${ }^{55}$ and the nanoscale cancer cures ${ }^{56}$ that might

50. See John Greenleaf Whittier, Maud Muller, in English Poetry III: From TennySON TO WHITMAN (Charles W. Gliot, ed., 1909) ("For of all sad words of tongue or pen, The saddest are these: 'It might have been!'”).

51. See Douglas A. Kysar, Preferences for Processes: The Process-Product Distinction and the Regulation of Consumer Choice, 118 HARV. L. REV. 525, 555 (2004) [hereinafter Kysar, Preferences for Processes] (describing biological evidence of genetic trait dispersion among neighboring plants from genetically modified crops).

52. See Douglas A. Kysar, Climate Change, Cultural Transformation, and Comprehensive Rationality, 31 B.C. ENVTL. AFF. L. REv. 555, 564-65 (2004) [hereinafter Kysar, Climate Change] (describing abrupt climate change scenarios).

53. See Joy, supra note 3 ("Among the cognoscenti of nanotechnology, this threat has become known as the 'gray goo problem.' Though masses of uncontrolled replicators need not be gray or gooey, the term 'gray goo' emphasizes that replicators able to obliterate life might be less inspiring than a single species of crabgrass. They might be superior in an evolutionary sense, but this need not make them valuable.").

54. See Adler, supra note 35, at 200 (describing "the creation of a new strain of rice fortified with additional Vitamin A" that may combat "vitamin A deficiency, which can cause blindness and other ills, [and which] affects up to 250 million children worldwide.").

55. See Bjørn Lomborg, The Skeptical Environmentalist: MEasuring the Real STATE OF THE WORLD 318 ("Despite our intuition that we naturally need to do something drastic about ... global warming, economic analyses clearly show that it will be far more expensive to cut $\mathrm{CO} 2$ emissions radically than to pay the costs of adaptation to the increased temperatures."). 
be foregone if society were to abstain from pursuing novel technologies and other uncertain endeavors.

There appears to be no limit to this brand of strong commensurability reasoning. For instance, some commentators contend that the mere act of expending money on regulatory compliance may create adverse health consequences, such that all of regulation truly is a risk-risk proposition. ${ }^{57}$ Similarly, although advocates of the risk-risk paradigm have yet to extend their approach to environmental harms, a plausible basis exists for doing so. Specifically, in light of the Environmental Kuznets Curve (EKC) literaturewhich purports to find a causal relationship between growth in national GDP per capita and environmental quality-analysts could argue that regulatory expenditures imply a necessary decline in environmental quality, such that regulation not only seems to entail an inherent health-health tradeoff, but an environmentenvironment one as well. ${ }^{58}$

Given this apparent pervasiveness of foregone benefits in the context of protective regulation-including especially benefits that would themselves take the form of improvements to human health or the environment-the logic of instrumentalist balancing and cost-benefit optimization might well seem inescapable. Nevertheless, as this Part describes, the preconditions for reliable balancing and optimization are not always satisfied in the environmental, health, and safety context. Instead, as the simplified classification scheme in Figure 1 shows, knowledge conditions can take diverse forms, ranging from the kind of well-characterized probability and outcome settings presupposed by CBA to the more stark conditions of uncertainty and ignorance that attract the at-

56. See Glenn Harlan Reynolds, Nanotechnology and Regulatory Policy: Three Futures, 17 HARV. J. L. \& TECH. 179, 186 (2003) (speculating that "specially designed nanodevices, the size of bacteria, might be programmed to destroy arterial plaque, or fight cancer cells, or repair cellular damage caused by aging.").

57. See, e.g., Frank B. Cross, When Environmental Regulations Kill: The Role of Health/Health Analysis, 22 EcoloGY L.Q. 729, 755 (1995); Ralph L. Keeney, Mortality Risks Induced by the Costs of Regulations, 8 J. RISK \& UNCERT. 95 (1994); Randall Lutter \& John F. Morrall III, Health-Health Analysis: A New Way to Evaluate Health and Safety Regulation, 8 J. RISK \& UNCERTAINTY 1 (1993); Randall Lutter, John Morrall, \& W. Kip Viscusi, The Cost-Per-Life-Saved Cutoff for Safety-Enhancing Regulations, 37 Econ. INQ. 599 (1999); W. Kip Viscusi, Regulating the Regulators, 63 U. CHI. L. REV. 1423, 1452-1453 (1996); Cass R. Sunstein, Health-Health Tradeoffs, 63 U. CHI. L. REV. 1533 (1996);W. Kip Viscusi \& Richard J. Zeckhauser, The Fatality and Injury Costs of Expenditures, 8 J. RISK \& UNCERT. 19 (1994).

58. See Douglas A. Kysar, Some Realism About Environmental Skepticism: The Implications of Bjørn Lomborg's The Skeptical Environmentalist for Environmental Law and Policy, 30 ECOLOGY L.Q. 223, 249-252 (2003) (describing and criticizing the Environmental Kuznets Curve literature). 
tention of PP proponents. ${ }^{59}$ Thus, a critical challenge for risk regulators is to ensure that their decisionmaking models are appropriately suited to the nature and degree of knowledge actually held, whether the models concern the assessment of ecological or human health hazards, the anticipation of social and economic consequences, or some more ambitious integration of all such empirical considerations.

Figure 1

\begin{tabular}{||l|l|l||}
\hline \hline & $\begin{array}{l}\text { OUTCOMES } \\
\text { WELL DEFINED }\end{array}$ & $\begin{array}{l}\text { OUTCOMES } \\
\text { POORLY } \\
\text { DEFINED }\end{array}$ \\
\hline $\begin{array}{l}\text { Probabilities Well } \\
\text { Defined }\end{array}$ & Risk & Ambiguity \\
\hline $\begin{array}{l}\text { Probabilities } \\
\text { Poorly Defined }\end{array}$ & Uncertainty & Ignorance \\
\hline
\end{tabular}

As this Part argues, the PP can be defended as a pragmatic decisionmaking heuristic that is particularly well-suited to the task of fostering consideration of how best to safeguard life and the environment under conditions of uncertainty and ignorance. Contrary to prominent critiques, the $\mathrm{PP}$ does not urge regulators "to be universally precautionary." 60 Instead, the PP focuses on particular categories of harm and separates them out for special treatment during early stages in the development of human knowledge and experience. Viewed sympathetically, this asymmetry of concern represents a procedurally rational mechanism for catalyzing empirical investigation, redressing political imbalances, and responding with prudence to threats of a potentially catastrophic or irreversible nature. Indeed, in many real world contexts, heuristic decisionmaking of the sort embodied in the PP expresses a kind of "ecological rationality" 61 - that is, a pragmatic decisionmaking approach that is both well-tailored to the informational and cognitive constraints of actual choice environments and capable of evolving and adapting over time.

59. Adapted from Andy Stirling, The Precautionary Principle in Science and Technology, in ReInTERPRETING THe PRECAUTIONARY PRINCIPLe, supra note 41, at 61, 79. The fourth possibility-ambiguity - seems only to attract the attention of game show hosts.

60. Sunstein, Beyond the Precautionary Principle, supra note 13, at 1008.

61. See Douglas A. Kysar et al., Group Report: Are Heuristics a Problem or a Solution?, in Heuristics AND The LAW 103, 112 (Gerd Gigerenzer \& Christoph Engel eds., 2005). 


\section{A. Complexity}

Much of the divide in risk regulation can be understood as a difference of view over which of the boxes in Figure 1 most accurately describes our policymaking predicament. ${ }^{62}$ As J.B. Ruhl has observed, "[t]he prevailing schools of environmental policy have described our problem as a series of linear, one-dimensional decisionmaking systems," an approach that assumes "economic conditions can be translated predictably into economic conclusions that call for prescribed economic measures, [and] environmental conditions can be translated predictably into environmental conclusions that call for environmental measures." 63 If indeed these prevailing schools are correct that biophysical and sociolegal systems are well-behaved-such that they follow linear operating rules, map onto normal or Gaussian probability distributions, and exhibit stable equilibrium outcomes - then data gaps and other shortcomings of human knowledge need not be viewed as deeply problematic.

If, on the other hand, these systems are complex-such that they exhibit "behaviors such as feedback, emergence, path dependence, and nonlinearity" 64 - then risk regulators face a fundamentally different task. Not only must they assess and manage risks of an uncertain magnitude, but they must do so within the context of numerous, overlapping dynamic systems, each of which is charac-

62. Compare David E. Adelman, The False Promise of the Genomics Revolution for Environmental Law, 29 HARV. ENVTL. L. REV. 117 (2005) (arguing that hope for revolutionary advances in environmental standard-setting from the emerging field of toxicogenomics is misplaced); Cary Coglianese \& Gary E. Marchant, Shifting Sands: The Limits of Science in Setting Risk Standards, 152 U. PA. L. REV. 1255, 1258 (2004); and Wendy E. Wagner, The Science Charade in Toxic Risk Regulation, 95 Colum. L. REV. 1613, with Daniel C. Esty, Environmental Protection in the Information Age, 79 N.Y.U. L. REV. 115, 124 (2003) (arguing that, although "pervasive uncertainties are simply assumed by most scholars to be part of the framework within which environmental law must operate," developments in information technology and other scientific fields promise to significantly reduce environmental uncertainty and increase the likelihood of regulatory efficacy).

63. Ruhl, Sustainable Development, supra note 41, at 46: See also Brian Wynne, Uncertainty and Environmental Learning: Reconceiving Science and Policy in the Preventive Paradigm, 2 GLOBAL ENVTL. CHANGE 111, 113 (1992) (observing that risk assessment was "originally developed for relatively very well structured mechanical problems" and that environmental systems, in contrast, "cannot be designed, manipulated and reduced to within the boundaries of existing analytical knowledge").

64. J.B. Ruhl \& James Salzman, Mozart and the Red Queen: The Problem of Regulatory Accretion in the Administrative State, 91 GEO. L. J. 757, 763 (2003). See also J.B. Ruhl \& Harold J. Ruhl, Jr., The Arrow of the Law in Modern Administrative States: Using Complexity Theory to Reveal the Diminishing Returns and Increasing Risks the Burgeoning of Law Poses to Society, 30 U.C. DAVIS L. REV. 405 (1997); J.B. Ruhl, Complexity Theory as a Paradigm for the Dynamical Law-and-Society System: A Wake-Up Call for Legal Reductionism and the Modern Administrative State, 45 DukE L. J. 849 (1996); Ruhl, Sustainable Development, supra note 41, at 46; J.B. Ruhl, Thinking of Environmental Law as a Complex Adaptive System: How to Clean up the Environment by Making a Mess of Environmental Law, 34 Hous. L. REV. 933 (1997). 
terized by such perplexing features as extreme sensitivity to minor variations in condition, ${ }^{65}$ "fat tail[]" probability distributions, ${ }^{66}$ and irreducible levels of uncertainty, or chaos. ${ }^{67}$ This is a far more intractable problem setting than has tended to be recognized in the risk regulation debate, even by those who critique CBA for its Herculean informational demands. Because complex adaptive systems contain ineliminable uncertainties that cannot be presumed to be insignificant, such systems by their nature are likely to present illposed problems - that is, problems whose imperviousness to resolution is not driven by deficiencies in our epistemic position, but rather by features inherent to the problems themselves.

CBA in particular may falter if risk regulation is characterized by complexity and uncertainty, given that adherence to the synoptic paradigm demands techniques and strategies for rendering policy spaces quantitatively tractable. ${ }^{68}$ In the view of some observers, the procedures adopted by proponents of the synoptic paradigm in response to this difficulty often are analytically and democratically unsatisfying. ${ }^{69}$ To be sure, defenders of CBA frequently respond to this charge by arguing that alternative approaches also are susceptible to mistake and manipulation, and

65. See Ruhl \& Salzman, supra note 64 , at 817-19.

66. See Daniel A. Farber, Probabilities Behaving Badly: Complexity Theory and Environmental Uncertainty, 37 U.C. DAVIS L. REV. 145, 152-55 (2003).

67. See id. at 153. This is not to suggest that the systems are indeterminate, but rather that their rules of operation give rise to stunningly complex and difficult-to-predict interactions. Extremely minor, even immeasurable variations in conditions between two otherwise identically situated systems—-such as the presence in one system of the proverbial flapping of a butterfly's wings - can give rise to dramatic differences in outcome between the two systems only a few evolutionary steps later. The resulting "chaos" is not randomness per se, but rather "order masquerading as randomness," a state of being that, although deterministic, nevertheless remains irreducibly uncertain. JAMES GLEICK, CHAOs: MAKING A NEW SCIENCE 22 (1987).

68. See OECD, The ECONOMic Appraisal of Environmental Projects and Policies: A PRACTICAL GUIDE 150 (1995) ("The treatment of uncertainty and risk looms large in environmental appraisal. Converting uncertainty into risk is essential to make the problem tractable.”); Richard T. Woodward \& Richard C. Bishop, How to Decide When Experts Disagree: Uncertainty-Based Choice Rules in Environmental Policy, 73 LAND ECON. 492, 505 (1997) ("If one considers a spectrum of choice problems from pure uncertainty to pure risk, almost all of the attention of economists has been on one extreme . . . This has led to policy advice and analysis that either implicitly or explicitly requires policymakers to divine probability distributions.").

69. As Amartya Sen and Bernard Williams put it, "Government House utilitarianism" such as that embodied in CBA risks becoming "an outlook favouring social arrangements under which a utilitarian élite controls a society in which the majority may not itself share those beliefs." Amartya Sen \& Bernard Williams, Introduction: Utilitarianism and Beyond, in UTILITARIANISM AND BEYOND 1, 16 (Amartya Sen \& Bernard Williams eds., 1982). Sen and Williams refer particularly to the partial disclosure conception of utilitarianism, in which élites apply the utilitarian calculus to social decisionmaking without disclosing their method of analysis, given the fear that its cold calculation might undermine the basis of social cohesion among citizens less capable of such enlightened reason. Compare Richard A. Posner, Our Incompetent Government, NEW REPUBLIC, Nov. 14, 2005, 23, 26 (decrying "the incapacity of our political class . . . to think in cost-benefit terms"). 
that the virtue of CBA is its requirement that regulators exhaustively identify and analyze the expected consequences of policy proposals. This argument, however, only explains why regulators should be required to provide a comprehensive survey of potential policy effects, not why such effects should be aligned along a single numerical metric. It is the latter requirement that often forces the CBA analyst to adopt methods of quantification and monetization that attract criticism.

A particularly clear demonstration of the critics' concern can be seen in certain quasi-scientific attempts by the FDA to control the scope of the risk assessment process by adopting a presumption that novel technological processes themselves are unworthy of heightened scrutiny. As noted above, ${ }^{70}$ such an assumption underlies the agency's determination that nanomaterials in consumer products such as sunscreens do not require an additional risk assessment if their macroscale counterparts have been previously evaluated. The assumption also may be located in the "substantial equivalence doctrine" that the FDA has used in the genetically modified agriculture context, and the "compositional analysis method" that it has proposed for use in the case of cloned livestock for human consumption. ${ }^{71}$ In all three cases, the FDA has made its risk assessment burden lighter by assuming that novel scientific processes (e.g., nanoscaling, genetic modification, cloning) are not in themselves cause for regulatory scrutiny or distinction, but rather only become relevant if they lead to manifest differences in the physical or compositional characteristics of end products as compared to conventional counterparts.

The flaws with such an assumption are many. ${ }^{72}$ For present purposes, the most significant shortcoming is the assumption's implicit view that "what we don't know won't hurt us." On the FDA's approach, situations of deep uncertainty regarding the potential impacts of novel technological processes are treated as unworthy of regulatory attention, an approach that reflects what Wendy Wagner has called the "unprecautionary principle." 73 Of course, the resulting permissive approach comports with the general tendency of liberal market democracies not to impede private action unless and until a public justification has been demonstrated. The confusion, however, is that this political predisposition has been presented in a scientific vernacular, as an assumption about the empirical ten-

70. See supra text accompanying note 10.

71. See Kysar, Preferences for Processes, supra note 51.

72. See id.

73. Wendy E. Wagner, The Precautionary Principle and Chemical Regulation in the U.S., 6 HUM. \& ECOL. RISK AssESSMENT 459, 466-68 (2000). 
dencies of nascent technologies. In the nanotechnology context, this approach seems especially inapt, given that scientists believe nanoscale materials are potentially revolutionary precisely because they display marked differences in chemical and physical behavior as compared to their macroscale equivalents. Assigning the burden of proof on such issues is therefore an inherently political exercise, one that should be seen as affecting the distribution of power and knowledge in society, rather than simply being derived from it.

Proponents of CBA have adopted more nuanced ways of dealing with incomplete information. Analysts sometimes contend, for instance, that the proper utilitarian response to situations of uncertainty is not to abandon the quest for optimization, as the PP appears to require, but instead to estimate and incorporate the costs and benefits of uncertainty directly into the optimization model. Although preferable to the FDA's blunt refusal to acknowledge uncertainty, this procedure still suffers from a basic limitation: Without knowing the expected value of future knowledge (which depends on the same unknown probabilities and outcomes that render the situation imperfectly characterized for purposes of risk assessment and CBA), the analyst cannot identify the point at which broadened regulatory inspection itself is no longer costjustified. Unwilling to concede uncertainty and ignorance, the analyst instead teeters on the edge of an infinite regress. ${ }^{74}$ In the context of complex adaptive systems, this problem is especially acute because the analyst cannot rely on a constant trend of diminishing returns from knowledge acquisition, given the possibility that minor perturbations in one period may give rise to dramatic effects many periods hence.

Introducing genetically modified organisms or nanomaterials widely into field environments raises similar concerns, given the practically irreversible nature of such action. For such decisions, proponents of CBA typically argue that the expectation calculus should be expanded to include whatever "option value" would be lost by engaging in an irreversible action with uncertain effects. ${ }^{75}$ For instance, one of the earliest and most significant papers in the environmental economics literature began by observing, "[I]f we are uncertain about the payoff to investment in development,

74. See Jonathan Baert Wiener, Managing the Iatrogenic Risks of Risk Management, 9 RISK 39, 73-74 (1998) (referring to the "optimal stopping problem" raised by such dilemmas).

75. See Kenneth J. Arrow \& Anthony C. Fisher, Environmental Preservation, Uncertainty, and Irreversibility, 88 Q. J. ECON. 312 (1974); C. Henry, Investment Decisions Under Uncertainty: The Irreversibility Effect, 64 AM. ECON. REV. 1066 (1974). For a leading efficiency model incorporating option values, see A. Myrick Freeman, The Sign and Size of Option Value, 60 LAND ECON. 1 (1984). 
we should err on the side of underinvestment, rather than overinvestment, since development is irreversible." 76 Proponents of the PP would, of course, wholeheartedly agree. They would not agree, however, that the option value of this precaution should simply be priced and incorporated into the efficiency calculus so that CBA can continue in "the usual way." 77 To PP adherents, such an exercise invites exclusionary, technocratic decisionmaking in the face of grave, uncertain collective choices-precisely the type of context that they believe instead requires inclusiveness, transparency, and candid acknowledgment that unavoidably moral choices are being undertaken. ${ }^{78}$

Most obviously susceptible to this critique is Delphi analysis, which is one prominent analytical method used by CBA practitioners to get the consequentialist-utilitarian ball rolling, despite the presence of true uncertainty. The Delphi technique consists essentially of gathering subjective assessments of unknown risks from a survey of experts in relevant fields. By then searching for a point of convergence among the expert responses, analysts hope to assign a Bayesian prior subjective belief that, in turn, will afford some nonarbitrary basis for taking a "first stab" at calculating expected outcomes. ${ }^{79}$ Proponents of CBA sometimes even deny that there is such a thing as uncertainty, apparently taking the view that if Bayesian rather than frequentist probability theory is adopted, some number always will be available to the cost-benefit optimizer. ${ }^{80}$ The question immediately raised, however, is: Whose subjective probability assessments will form the basis of the Bayesian exercise? Without devoting careful attention to concerns of inclusiveness and participatory legitimacy, environmental policymakers risk obscuring essentially normative judgments through

76. See Arrow \& Fisher, supra note 75, at 317.

77. Id. at 319 .

78. See Wynne, supra note 63, at 115 (arguing that "institutionalized exaggeration of the scope and power of scientific knowledge creates a vacuum in which should exist a vital social discourse about the conditions and boundaries of scientific knowledge in relation to moral and social knowledge.”).

79. For discussion of Bayesian probability theory, see David E. Adelman, Scientific Activism and Restraint: The Interplay of Statistics, Judgment, and Procedure in Environmental Law, 79 Notre Dame L. ReV. 497 (2004); Matthew D. Adler, Against "Individual Risk": A Sympathetic Critique of Risk Regulation, 153 U. PA. L. REV. 1121 (2005); Stephen Charest, Bayesian Approaches to the Precautionary Principle, 12 DUKE ENVTL. L. \& POL'Y F. 265 (2002). As Charest points out, the Bayesian approach may be an improvement over risk assessment techniques that incorporate subjective assumptions through less transparent means.

80. See Dexter Samida \& David A. Weisbach, Paretian Intergenerational Discounting, 74 U. CHI. L. REV. _ (forthcoming 2007) (stating that the authors "are not sure that Knightian uncertainty is a meaningful category"). 
an exercise that, when properly understood, often merits only a weak case for deference. ${ }^{81}$

Other approaches used by CBA practitioners when faced with true uncertainty include Monte Carlo analysis and similar statistical methods for generating hypothetical distributions of unknown probabilities. These computer techniques evaluate the effects of policy proposals under thousands of different states of the world such that, even in the face of uncertainty, analysts may be able to locate policy prescriptions that predominate over a wide range of possible conditions. ${ }^{82}$ Such techniques depend, however, on the specification of certain assumptions about the theoretical nature of unknown probabilities and, in keeping with the classical scientific tradition, analysts typically specify normal or Gaussian probability behavior. ${ }^{83}$ When applied to systems that behave, instead, according to the laws of complexity, such assumptions can lead to dramatically erroneous policy advice, despite the great technological sophistication of the Monte Carlo procedure. ${ }^{84}$

81. Scholars from the AEI-Brookings Joint Center for Regulatory Studies, for instance, have proposed the use of Delphi techniques to fill data gaps in regulatory analysis, yet their own use of the methodology to argue against the desirability of environmental, health, and safety regulation raises cause for skepticism. See Robert W. Hahn \& Rohit Malik, Is Regulation Good for You?, 27 HARV. J. L. \& PUB. POL’Y 893, 898 n.21 (2005). In what amounts to an ad hoc opinion poll, "leading regulatory economists" were asked to estimate the percentage of major environmental, health, and safety regulations implemented between 1993 and 2002 that would have passed a cost-benefit test if the economists themselves were performing the analysis. See id. at 902 . Researchers from the Center implicitly concede the deeply subjective nature of this exercise when they note that survey respondents were chosen to be "fairly evenly distributed in terms of their political affiliation"-a control measure that should not have been necessary if CBA really offered the objective policy advice that its more zealous adherents proclaim. Id. In the end, it is unclear what the researchers intended to contribute with the survey, except perhaps confirmation that many economists distrust federal agencies and the democratic process. Cf. id. at 907 (describing "one of [the authors'] wilder dreams" in which CBA is used to "mak[e] each agency really sing for its supper").

82. See William D. Nordhaus, MANaging The Global Commons: The Economics of Climate Change 184 (1994). For a discussion of how Monte Carlo procedures are used in toxic risk assessment, see Susan R. Poulter, Monte Carlo Procedures in Environmental Risk Assessment-Science, Policy and Legal Issues, 9 RISK 7 (1998).

83. See Judson Jaffe \& Robert N. Stavins, AEI-Brookings Joint Center for REGUlatory Studies, The VAlue of Formal QuANTITATIVE ASSESSMENT OF UNCERTAinTY IN REGULATORY ANALYSIS (2004), http://www.aei.brookings.org/admin/authorpdfs/page.php? $\mathrm{id}=1045$.

84. A salient example from finance theory helps to elucidate this point. Reflecting their classical assumptions, conventional models of financial markets tend to deny the likelihood that stock market crashes will occur with the magnitude that we have, nonetheless, experienced on multiple occasions in the previous century. See BENOIT MANDELBROT \& RICHARD L. Hudson, THE (Mis)BEHAVIOR OF MARKETS 4-5 (2004). This denial could be explained in one of two ways. On the one hand, we could be experiencing inconceivably bad luck during this period in our history such that later, when averaged over subsequent crash-free millennia, the infinitesimal risk predicted by Gaussian financial models will turn out to be vindicated. On the other hand, it could be that our models are wrong and that, as Daniel Farber puts it, "it is reasonably foreseeable that non-reasonably foreseeable events will occur from time to time." Farber, supra note 66, at 146. 


\section{B. Catastrophe}

Criticisms of CBA's efforts to grapple with complexity and uncertainty have particular purchase in the case of potentially catastrophic risks. As Judge Richard Posner's recent book notes, humanity faces a number of threats of uncertain, but possibly monumental consequence, including some threats that might entail the erasure of all life on the planet. ${ }^{85}$ In the face of such complete catastrophic threats, conventional approaches to CBA would, first, sum up the total monetary-equivalent worth of the expected human population at the time of potential destruction and, second, discount that number, both for time and for likelihood.86 The resulting number would, of course, be finite. It might also be quite small, particularly if the anticipated disaster looms far in the future or with minute probability. One could increase the number to reflect a degree of risk aversion, but the result still would be finite and, if cost-benefit analyses of climate change are an indication, ${ }^{87}$ not alarmingly large.

The question then arises whether the expectation calculus of CBA is appropriately textured for the type of decision actually being confronted. We have ruled out infinite values by assumption $^{88}$ and our methodology devotes only indirect attention to vari-

85. See Posner, Catastrophe, supra note 18, at 21 ("The number of extreme catastrophes that have a more than negligible probability of occurring in this century is alarmingly great, and their variety startling.").

86. Initially, one might expect that CBA would value an outcome of complete destruction at precisely zero, given that CBA tends to measure all welfare consequences from the perspective of individual preferences and, by assumption, no individuals would remain to express such preferences following an apocalyptic event. $C$ f. infra text accompanying notes 152-153 (observing that some CBA proponents argue present generations have no moral obligations at all with regard to future generations). As Matthew Adler has argued, however, death can be thought of as a welfare setback, even for the person who expires. See Adler, supra note 79 , at 1200 . The thought project forces the analyst to determine whether utility is better assessed ex ante or ex post. In this case, given the hypothesized annihilation of all potential evaluators, only ex ante figures could be used. As Adler notes, economists in general tend to use ex ante preference assessments. See id. Psychologists, on the other hand, find large and systematic deviations between the two assessment frames, raising in the process important questions about the nature of utility and well-being. See generally Daniel Kahneman et al., Well-Being: The Foundations of Hedonic Psychology (1999).

87. See Kysar, Climate Change, supra note 52, at 570.

88. The tenets of rational choice theory break down when applied to gambles involving infinite value stakes. Most notably, the standard rationality assumption of continuity, which ensures that individuals can make tradeoffs between all relevant outcomes, is violated by the introduction of infinite utility outcomes. Scholars tend to respond to this complication either by developing entirely new formulations of decision theory that are capable of grappling with infinite utilities, or simply by ruling such utilities inadmissible in order to maintain the theoretical consistency of their framework. The former approach requires abandoning much of the conventional statistical approach to decisionmaking, including the laws of large numbers and, correspondingly, confidence that the concepts of expectation and risk aversion together provide a satisfactory guide for decisionmaking. The latter approach 
ance, through the risk aversion adjustment. As a result, we have come to contemplate the "end of life as we know it" with a soberness that might appear, to many, irrational. Unlike repeat-play monetary gambles, for which probabilistically-determined outcomes provide an invaluable source of information, expectation seems to provide a poor decision guide for irreversible or catastrophic events. Put bluntly, either nanotechnology will transform the planet into "gray goo" or it will not. We do not know what the precise probabilities involved are, but given the nature of discontinuity, we do know that the expected utility outcome-the weighted average of these extremes-will not occur. ${ }^{89}$ Thus, by displacing context-sensitive discussion of precisely what outcomes are being gambled in favor of what gains and for which winners and losers, the CBA approach tends to understate the challenge posed by longterm catastrophic risks.

In light of such concerns, one might be tempted to carve out irreversible or catastrophic risks for special treatment, leaving CBA to serve as the predominant method for evaluating more routine environmental, health, and safety decisionmaking. ${ }^{90}$ The teachings of complexity theory, however, suggest that much of our understanding of "routine" risk regulation is misguided. The problem of irreversibility, for instance, should not be seen as restricted to one-shot disaster scenarios. Rather, given the presence of sensitivity, feedback loops, and other features of path dependence, some degree of irreversibility should be expected to characterize all decision nodes within complex adaptive systems. ${ }^{91}$ Indeed, if the teachings of complexity theory are

is obviously more theoretically tidy, but seems unacceptable so long as the idea of infinite values appears both meaningful and practically relevant to some actual decisions.

89. As Posner notes, "by definition, all but the last doomsday prediction is false." PosNER, CATASTROPHe, supra note 18, at 13. The standard view of CBA defenders instead seems to be that, "[w]e live in a continuous world." Robert H. Frank, Why is Cost-Benefit Analysis So Controversial?, 29 J. LEGAL STUD. 77, 78 (2000).

90. See Cass R. Sunstein, Cost-Benefit Analysis and the Environment, supra note 35; Cass R. Sunstein, Irreversible and Catastrophic (Univ. Chicago John M. Olin Law \& Econ. Working Paper No. 242, 2d Series 2005) available at http://papers.ssrn.com/sol3/papers. cfm?abstract_id=705323.

91. Sunstein argues further that irreversibilities should be seen to lie "on all sides" of the risk regulation equation, given that precautionary regulations may create their own irreversible effects, such as "increased dependence on nuclear energy" in the case of greenhouse gas mitigation policies. Sunstein, Irreversible and Catastrophic, supra note 90, at 20. This argument appears to embrace the teachings of complexity theory, in the sense that systems such as the atmosphere or the regulated market are seen as likely to exhibit path dependency, feedback effects, and other tendencies toward irreversibility. Sunstein does not, however, engage the broader challenge posed by complexity theory to synoptic decisionmaking approaches such as CBA. Like the radical commensurability implications of the "riskrisk," "health-health," and "environment-environment" arguments, see supra text accompanying notes 57-58, Sunstein's "irreversibility-irreversibility" argument challenges far more than simply the conceptual underpinnings of the PP. It also problematizes the very basis on which moral decisionmaking gains traction, since it serves to erode the conceptions of dis- 
sound, then environmental, health, and safety dilemmas will, almost by definition, present ill-posed problems that contain "nasty surprises"92 and other computationally intractable features. As the next Section explains, such features of complex, adaptive systems raise the possibility that pragmatic decisionmaking procedures such as the PP may prove more "ecologically rational" than formal analytical devices such as CBA.

\section{Procedural Rationality}

In the context of complex, adaptive systems, the deliberate attempt to optimize may not represent simply an imperfect, but useful aid to decisionmaking, as CBA defenders often assert. ${ }^{93}$ Rather, it may represent a solution concept that is poorly matched for the problem tasks at hand. In the face of ill-posed problems, we cannot confidently expect that the errors of CBA will cluster around an "optimal" result-indeed, for such problems the very notion of an optimum eludes meaningful description. The errors of CBA therefore are capable of deviating substantially and unpredictably from decision paths that are easily identified as desirable_-if not necessarily optimal-through less formalistic decision procedures. In light of such concerns, proponents of the PP consciously part ways with the technocratic paradigm underlying risk assessment and CBA. Rather than insist on quantification as a predicate to decisionmaking, ${ }^{94}$ they instead argue that environ-

tinctive human agency that underwrite a great deal of our moral reasoning and may even provide the fulcrum on which it ultimately depends. See infra text accompanying notes 211225.

92. Farber, supra note 66 , at 167.

93. See, e.g., Cass R. Sunstein, The Cost-Benefit State: The Future of RegulaTORY PROTECTION 25-26 (2002) ("The strongest arguments for CBA seem to rest not with neoclassical economics but with common sense, informed by behavioral economics and cognitive psychology."); SUNSTEIN, LAWS OF FEAR, supra note 19, at 149 (defending CBA for its ability to "produce useful information" and "increase the coherence of programs that would otherwise be a product of some combination of fear, neglect and interest-group power"); SUNSTEIN, RISK AND REASON, supra note 19, at ix ("[C]ost-benefit analysis should be seen as a simple pragmatic tool, designed to promote a better appreciation of the consequences of regulation.”).

94. Hahn and Malik are particularly insistent on this point. After noting that many federal regulations offer benefits that have been left unquantified by adopting agencies, the authors first skeptically observe that "[t]he question naturally arises as to whether there are really benefits to those regulations." Hahn \& Malik, supra note 81, at 895. Then, as part of their effort to assess the costs and benefits of major regulations, the authors simply assign "zero benefits" to those regulations for which benefits were left unquantified by the relevant agency. See id. at 898. To defend this procedure, Hahn and Malik state that "any other assumption seems totally arbitrary." Id. But assigning zero is no more or less arbitrary than assigning any other number would be in this situation. Instead, what is truly arbitrary is insisting on a quantified value under circumstances in which quantification cannot reliably proceed. See Woodward \& Bishop, supra note 68, at 506 (arguing that "if the 
mental, health, and safety regulation should become infused with a "culture of humility about the sufficiency and accuracy of existing knowledge." 95

As it turns out, the United States has enjoyed a long and successful experience with precisely this approach. Despite the current prominence of CBA among U.S. policymakers and academics, much of U.S. environmental law and regulation continues to be based instead on policies and procedures that reflect a precautionary approach. In several key pollution control areas, for instance, the United States has forsaken optimization in favor of a precautionary practice of requiring installation of the best available pollution abatement technology, ${ }^{96}$ often with opt-out procedures extended to firms that are able to demonstrate achievement of equal abatement levels using alternative technologies. ${ }^{97}$ This simple heuristic_-in essence, "do the best you can"98_implies great collective commitment to the preservation of human life and the environment without requiring satisfaction of Herculean informational demands by regulators. ${ }^{99}$

decision maker does not possess well-defined probabilities, then the use of ad hoc probabilities is not rational").

95. Stirling, supra note 59, at 66. See also Donald T. Hornstein, Reclaiming Environmental Law: A Normative Critique of Comparative Risk Analysis, 92 COLUM. L. REV. 562 (1992).

96. As Richard Stewart has noted, one frequently offered interpretation of the PP is that the best available pollution control technology should be required of all proponents of activities with uncertain environmental, health, or safety threats. See Richard B. Stewart, Environmental Regulatory Decisionmaking Under Uncertainty, in 20 RES. IN L. AND ECON. 71, 78 (Timothy Swanson ed., 2002).

97. See Daniel Bodansky, The Precautionary Principle in US Environmental Law, in INTERPRETING THE PRECAUTIONARY PRINCIPLE (Timothy O'Riordan \& James Cameron eds., 1994). See also Adam Babich, Too Much Science in Environmental Law, 28 Colum. J. ENVTL. L. 119, 125 (2003) ("The requirement of best available technology embodies a policy judgment as attractive as apple pie."); Howard Latin, Ideal Versus Real Regulatory Efficiency: Implementation of Uniform Standards and "Fine-Tuning" Regulatory Reforms, 37 STAN. L. REV. 1267, 1283-84 (1985) (noting Congress repeatedly "chose to emphasize the need for prompt injury prevention over the need for an optimal balance between regulatory benefits and costs" in its landmark 1970s legislation); Thomas O. McGarity, The Goals of Environmental Legislation, 31 B.C. ENVTL. AFF. L. REV. 529, 538-545 (2004) (reviewing examples); Wendy E. Wagner, The Triumph of Technology-Based Standards, 2000 U. ILL. L. REV. 83 (attributing much of the success of pollution reduction in the modern environmental era to technology-based standards). Significant early environmental court decisions also emphasized the precautionary basis of U.S. risk regulation. See Reserve Mining Co. v. E.P.A., 514 F.2d 492 (8th Cir. 1975); Ethyl Corp. v. E.P.A., 541 F.2d 1, 28 (D.C. Cir. 1976).

98. See Wagner, supra note 97 , at 92 .

99. Moreover, in practice, the approach tends to produce results similar to those of a "knee of the cost curve" decisionmaking heuristic, in which pollution abatement is required at least to the point at which marginal returns from further abatement begin to steeply decline. See Thomas O. McGarity, The Internal Structure of EPA Rulemaking, 54 LAW \& CONT. PROB. 57, 62 (1991). In this manner, the "best available control technology" requirement demonstrates some cost-sensitivity (or proportionality) without depending on unrealistic and controversial assumptions regarding the ability of regulators to equalize the marginal costs and benefits of abatement. The policy standard instead assumes that the hazards of pollution are sufficiently severe and unpredictable that only the "best" effort at pre- 
Realistic but unquantifiable threats of catastrophic loss present an additional case in which heuristic decisionmaking procedures may prove more pragmatically sensible than deliberate cost-benefit optimization. With regard to climate change, for instance, future generations may reflect with marvel on our present day attempts to meticulously calculate the costs and benefits of greenhouse policies. Such studies typically lead to a conclusion that the economic benefits of continued fossil fuel consumption more than outweigh the physical, agricultural, and ecological costs that would be averted by restricting emissions, at least for the next few decades. Accordingly, the optimal carbon reduction policy under CBA is a rather limited one that should not begin any time soon. ${ }^{100}$ The important lesson from complexity theory, again, is that the apparent CBA consensus on climate change may not merely be wrong; it may be wildly wrong. Especially in light of the relatively minor cost associated with implementing most proposed carbon emissions abatement policies, uncertain but potentially catastrophic consequences of anthropogenic greenhouse gas emissions should not simply be reduced to an expectation value and included within cost-benefit calculation. ${ }^{101}$

Along these lines, a growing number of scientists and policymakers have begun to focus attention on the stabilization of greenhouse gas concentrations at a level that is hoped to be sufficiently low to eliminate the possibility of truly disastrous climate change scenarios. ${ }^{102}$ By advocating the limitation of human emissions to a point that will avoid exceeding this critical level whatever the cost, proponents eschew optimization and instead adopt something more closely resembling the "safe minimum standards" approach that is familiar from the economic literature on endangered species regulation. ${ }^{103}$ Recognizing that climate change, like

vention will suffice. Such an aspirational standard should not be seen as reflecting a naïve belief in the possibility of a "zero risk" society. See W. Kip Viscusi, Equivalent Frames of Reference for Judging Risk Regulation Policies, 3 N.Y.U. ENVTL. L. J. 431, 465 (1995). Instead it reflects a sensitive appreciation both of the practical difficulties of crafting, defending, and enforcing pollution control standards, and of the deeply moral connotations that our legal pronouncements entail. See infra text accompanying notes 169-170 (discussing the "moral remainder" that accompanies the tragic choices entailed by risk regulation and that cannot be subsumed by the cost-benefit procedure).

100. See LOMBORG, supra note 55, at 318 (noting that "economic analyses clearly show that it will be far more expensive to cut $\mathrm{CO} 2$ emissions radically than to pay the costs of adaptation to the increased temperatures.").

101. See Kysar, Climate Change, supra note 52, at 563-64.

102. See id. at 565-66.

103. Richard C. Bishop, Endangered Species And Uncertainty: The Economics Of A Safe Minimum Standard, AM. J. AGRIC. ECON. 10 (Feb., 1978); S.V. CiriaCy-WANTRuP, RESOURCE Conservation: ECONOMiCs AND Policies (1st ed., 1952). See also Barton H. Thompson, Jr., People or Prairie Chickens: The Uncertain Case for Optimal Biodiversity, 51 STAN. L. REV. 1127, 1159-63 (1999) (reviewing and critiquing the "safe minimum standards" literature). 
species preservation, is characterized by uncertainty, irreversibilities, critical thresholds, and other hallmark features of complexity, proponents argue that society should establish "safe minimum standards . . . for protecting Earth's life-support systems in the face of virtually inevitable unpleasant surprises."104

This "safe minimum standards" approach has long been associated with the PP. ${ }^{105}$ One also may think of the "safe minimum standards" approach as resembling the maximin principle from decision theory, which counsels minimization of the maximum possible loss when decisionmakers are faced with policy choices that are characterized by true uncertainty. ${ }^{106}$ Most famously discussed by John Rawls in the context of elaborating an egalitarian theory of justice, ${ }^{107}$ the maximin principle reflects what would be termed an extreme degree of risk aversion if probabilistic information on outcomes were actually available, given that the principle focuses attention exclusively on the worst case outcome from each possible course of action under inspection. For this reason, the principle has attracted a substantial share of criticism. ${ }^{108}$ Nevertheless, at least as a preliminary stance, proponents of the PP believe that an extreme level of risk aversion is appropriate for policymaking that concerns unknown but potentially devastating threats to the global climate, the ozone layer, biodiversity, and other natural systems that are thought to be of fundamental and irreplaceable importance to humanity.

Whether characterized as the PP, the best available technology requirement, the safe minimum standard, or the maximin principle, each of these related decisionmaking techniques reflects an awareness that truly rational risk regulation sometimes re-

104. Paul R. Ehrlich, Ecological Economics and the Carrying Capacity of the Earth, in NATURAl CAPital: The Ecological APPROACH to SustainabiLity 38, 49 (A. Jansson et al, eds., 1994).

105. See T.M. Crowards, Combining Economics, Ecology and Philosophy: Safe Minimum Standards of Environmental Protection, in VALUATION AND ENVIRONMENT: PRINCIPLES AND PRACTICES (M. O'Connor \& C. Spash eds., 1997); O'Riordan et al, The Evolution of the Precautionary Principle, supra note 41, at 23.

106. Indeed, as Sunstein notes, the maximin principle shares much conceptual space with the PP, given that both principles direct "officials to identify the worst case among the various options, and to select that option whose worst case is least bad." Sunstein, Beyond the Precautionary Principle, supra note 13, at 1033.

107. But see Derek Parfit \& John Broome, Rawlsian Principles, in DeREK PARFIT, REASONS AND PERSONS, appendix H (1984) (observing an important, but subtle conceptual distinction between Rawls's difference principle and maximin).

108. See John C. Harsanyi, Can the Maximin Principle Serve as a Basis for Morality? A Critique of John Rawls's Theory, 69 AM. PoL. SCI. REV. 594 (1975). Much of this criticism, however, overlooks the conditions that Rawls presupposed for appropriate use of the maximin principle: settings of true uncertainty involving a worst-case outcome of "grave risks" which could be avoided by sacrificing a potential gain that is of comparatively insubstantial moment. PP proponents believe that current environmental policy issues such as climate change fit these conditions well. See supra text accompanying notes 101-104. 
quires officials to abandon the quest for optimization in favor of less ambitious, more pragmatically sensible approaches. Of course, the extreme conservatism of these approaches begs the questions of when and how to relax their dictates in favor of more permissive standards. According to many PP supporters, however, fostering such an adaptive approach to risk regulation is precisely the point of the $\mathrm{PP}$-something that the principle's critics seem reluctant to acknowledge. Unlike the optimization framework of CBA, which must resort to awkward analytical devices in the presence of imperfectly characterized risks, the PP's incremental approach reflects great sensitivity to the fact that effective decisionmaking in the face of many problems demands procedural rationality. ${ }^{109}$

The policymaking paradigm of "adaptive management" often is seen as a natural candidate to provide the kind of incremental, dynamic decisionmaking procedure envisioned by PP proponents. ${ }^{110}$ Pioneered by biologist C.S. Holling, ${ }^{111}$ adaptive management is an application of "the concept of experimentation to the design and implementation of natural-resource and environmental policies."112 Because uncertainty and evolutionary change are presumed to be foundational characteristics of both biophysical and sociolegal systems, the adaptive management approach does not seek to identify static "optimal" equilibria. Instead, it aims to utilize constant feedback and experimentation in order to ensure the long-run sustainability of vital ecological processes. The concept of sustainability, in turn, entails judgments that cross not only the boundaries between scientific disciplines, but also the real and imagined boundaries that exist between science and politics. ${ }^{113}$ The

109. See Brian J. LOASBy, Choice, CoMPlexity AND IgNORANCE: AN ENQUiRy INTO Economic Theory AND the Practice OF DeCision-MAKing 220 (1976) ("A theory which takes serious account of time and ignorance must be a theory of processes, not of states-not even of dynamic states."); Schrader-Frechette, supra note 33, at 27 ("Decision-theoretic rules under uncertainty require scientists to take account of the fairness of the allocation process, not merely the outcomes.").

110. See A. Dan Tarlock, Is There A There There In Environmental Law?, 19 FLA ST. U. J. LAND USE \& ENVTL. L. 213, 252 (2004) ("The precautionary principle needs to be linked to the idea of adaptive management. The existence of monitoring and adaptive feed-back mechanisms should be a major factor in validating the decision to limit an activity when the adverse impacts are uncertain.”).

111. See AdAPtive EnVIronmental Assessment and Management (C.S. Holling ed., 1978).

112. See Kai N. Lee, Compass and Gyroscope 53 (1993). See also John Copeland NAGLE \& J.B. RuHL, THE LAW OF BIODIVERSITY AND ECOSYSTEM MANAGEMENT (2002); Norman L. Christensen, The Report of the Ecological Society of America Committee on the Scientific Basis for Ecosystem Management, 6 ECOLOGICAL APPLICATIONS 665 (1996) (describing ecosystem management as "driven by explicit goals, executed by policies, protocols, and practices, and made adaptable by monitoring and research based on our best understanding of the ecological interactions and processes necessary to sustain ecosystem composition, structure, and function").

113. See Kysar, Sustainable Development, supra note 46, at 2114. 
ultimate aim of adaptive management, therefore, is the rather grandiose one of "integrat[ing] scientific knowledge of ecological relationships within a complex sociopolitical and values framework toward the general goal of protecting native ecosystem integrity over the long term" 114

As part of this "complex sociopolitical and values framework," proponents believe that the PP can play a central information-forcing role. Unlike their CBA counterparts, proponents of the $\mathrm{PP}$ recognize that uncertainty itself is a subject of power, influence, and control within economically advanced societies. Thus, the content of scientific knowledge and the manner of its production are not treated exogenously by the PP, but instead are made a central focus of the regulatory program. Shifting the burden of proof onto the promoters of new technologies and activities, as many proponents of the PP urge, serves the practical purpose of providing incentives for research and understanding by those parties who are thought to be best able to develop knowledge of imperfectly characterized threats. ${ }^{115}$ The CBA/risk assessment paradigm, in contrast, seems to assume that scientific uncertainty-the single most salient feature of environmental, health, and safety regulation-is simply addressed "out there." 116 Such epistemic bravado entails great opportunity costs, for the regulatory approval process itself can offer a powerful institutional mechanism for reducing the scientific uncertainties that riddle environmental, health, and safety law. ${ }^{117}$

\section{THE PROBLEM OF VALUATION}

One of CBA's most vaunted virtues is its ability to synthesize vast amounts of empirical information regarding policy conse-

114. R. Edward Grumbine, What is Ecosystem Management?, 8 Conservation BIoLOGY 27, 31 (1994)

115. See Amy Sinden, Cass Sunstein's Cost-Benefit Lite: Economics for Liberals, 29 CoLUM. J. ENVTL. L. 191, 194 (2004) (observing that precautionary regulatory approaches such as absolute standards "perform a crucial power-shifting function, leveling the political playing field between diffuse and powerless public interests and concentrated monied corporate interests").

116. Cf. Wendy E. Wagner, Commons Ignorance: The Failure of Environmental Law to Produce Needed Information on Health and the Environment, 53 DukE L. J. 1619, 1624 (2004) (criticizing "the failure of the environmental laws to require production of basic information about the harms caused by polluting activities and hazardous products").

117. No doubt, proponents of optimization would protest that uncertainties exist on both the risk and the benefit side of such dilemmas. Market actors, however, already have strong incentives to demonstrate (and to capture) the benefits of their activities and technologies. See Jon D. Hanson \& Douglas A. Kysar, Taking Behavioralism Seriously: A Response to Market Manipulation, 6 Roger WILliams U. L. REV. 259, 271-72 (2000). In that sense, the PP's asymmetry of regulatory concern can be seen as responding to an underlying asymmetry of knowledge incentives within the unregulated market. 
quences into a single analytical framework. As Gödel famously demonstrated, however, no formal system of minimal complexity can be both consistent and complete. ${ }^{118}$ Because consistency generally is taken to capture the essence of rationality, practitioners of CBA typically respond to Gödel's challenge by sacrificing completeness; that is, they treat certain decision criteria as externally given in order to maintain the consistency of their CBA outputs. ${ }^{119}$ Thus, despite the widespread view that CBA encompasses a broader range of concerns than the $\mathrm{PP}$, it is only the CBA procedure that must-by its very nature-ignore at least some parameters of a given decisionmaking context. Practitioners of CBA generally attempt to minimize this complication by exogenizing elements that are thought to be of little practical import or that are believed to be adequately addressed by other institutional mechanisms, such as the tax and transfer system. The problem with this otherwise sensible strategy is that, increasingly, CBA is being offered for use in choice settings, first, where the variables exogenized are of deep and unmistakable significance to the very decision under inspection and, second, where the potential role of alternative governance mechanisms is being displaced by the CBA exercise itself.

As described in the previous Part, questions concerning how the relevant political community should behave in the face of uncertainty regarding potentially irreversible or catastrophic consequences of human action are often subsumed by technical assumptions in risk-assessment and CBA procedures. Also missing or obscured are questions concerning, first, how the political community should respond to the fact that not only private values, but also social meanings, sometimes are affected by new technologies, shared experiences, or collective decisionmaking processes; and, second, how the community should regard non-nationals, future generations, and other interest-holders who are not already granted full membership in the community of individuals comprising the interest-optimization substrate. Both of these sets of questions require mechanisms for fostering democratic dialogue and

118. See Kurt Gödel, On Formally Undecidable Propositions of Principia Mathematica and Related Systems, in JEAN VAN HEIJENOORT, From FrEGE TO GODEL: A SOURCE Book on Mathematical Logic 178 (Harvard Univ. Press 1967). See also John D. Barrow, IMPOSSIBILITY: THE LIMITS OF SCIENCE AND THE SCIENCE OF LIMITS 218-247 (1998); PAUL W. Glimcher, Decisions, Uncertainty, AND the Brain: The Science of Neuroeconomics 72 (2003); Guiseppe Dari Mattiacci, Gödel, Kaplow, Shavell: Consistency and Completeness in Social Decisionmaking (George Mason Sch. of Law \& Econ. Working Paper Series, Paper No. 03-55, 2004) available at $\mathrm{http} / / / \mathrm{ssrn} . c o m / a b s t r a c t=470122$.

119. Cf. Clive L. Spash, Greenhouse Economics: Values AND Ethics 267 (2002) ("Optimality . . . is in fact consistency analysis and the best outcome is not guaranteed by the model, but only the choice that is consistent with the assumptions."). 
developing new collective norms of responsibility. Yet, as this Part demonstrates, the questions are taken by CBA as having already been essentially answered.

\section{A. Emergence}

CBA practitioners generally adopt a preferentialist account of welfare in which individuals' expressed, revealed, or hypothesized preferences are taken to supply the exclusive criterion for valuing the expected consequences of social choice. Yet, as Mark Sagoff has argued, CBA practitioners have no non-normative procedure for deriving individual preference functions. ${ }^{120}$ That is, despite the oft-heard claim that revealed preference studies represent "in fact reflections of individual preferences, and hence utility," ${ }^{21}$ the interpretation of observed behavior is actually a slippery exercise in which the analyst must adopt a series of assumptions about the available opportunities and choice criteria that confront observed individuals. At times, these assumptions appear to rest more on personal introspection and professional custom than on sustained engagement with the actual circumstances of observed individuals. As Sagoff puts it, "[c]hoice is at best a conceptual construct inferred from ad hoc descriptions of behaviordescriptions that themselves presuppose beliefs about available options and therefore about preferences." 122

To give one pertinent example, many of the data interpretation challenges found in employment market value-of-life studieswhich provide empirical estimates for use in policymaking of individuals' willingness-to-pay to avoid risks of death or injury to themselves-arise from the fact that the United States has managed to drastically reduce its occupational hazard levels over the course of the past century. For this reason, the remaining segments of the economy that exhibit an occupational mortality rate high enough to support the wage-risk premium methodology tend to be segments populated by those with the least social, economic, and political capital—variables that themselves can be expected to influence the opportunity set and the resulting preference orderings of observed individuals. ${ }^{123}$ Thus, what the CBA analyst re-

120. See Mark Sagoff, Price, Principle, AND the Environment 57-79 (2004).

121. W. Kip Viscusi, Risk Equity, 29 J. LeGAL Stud. 843, 849 (2000) (emphasis added). Compare Amartya Sen, Rational Fools, in Choice, Welfare, And MEasurement 84-106 (1982).

122. SAGOFF, supra note 120 , at 77.

123. According to one study, for instance, the implicit value-of-life revealed by wagerisk interactions appears to be several million dollars higher for union workers than for non-union workers, holding constant other significant variables. See Peter Dorman \& Paul 
gards as choice (and hence preference (and hence utility)), may actually capture in part the analyst's inclination to treat pre-existing power relations in employment markets as normatively privileged. ${ }^{124}$

Further room for confusion under CBA arises from the counterfactual nature of opportunity cost assessment. ${ }^{125}$ In one prominent study of climate change, for instance, the analyst's decision to add a variable representing enhanced recreation opportunities in a warmer world resulted in monetized benefits that tended to swamp the impact of estimated morbidity and mortality. ${ }^{126}$ Apart from being unduly wooden-why assume, after all, that individuals will continue to value mountain biking at the same amount if they know that their extra days of recreation have been funded through an increase in malaria among the equatorial poor? ${ }^{127}$ - this exercise also is open to considerable selection bias. In a real sense, climate change has the potential to affect every biophysical and sociolegal system on the planet, systems about which our present understanding is highly incomplete and imperfect. To choose among such effects and offer the resulting calculation as comprehensive is convincing, one suspects, only because the ritual comports with our deeply ingrained desire to imagine our most difficult policy choices as purely scientific or technical in nature.

This is not to suggest that the analyst could, even in theory, conduct a thoroughgoing preferentialist account of climate change. The degrees of uncertainty in the relevant parameters-and the degrees of freedom available to the cost-benefit analyst in choosing which aspects of which systems to hold constant-render the pro-

Hagstron, Wage Compenation for Dangerous Work Revisited, 52 INDUSTRY \& LABOR RELA. TIONS REV. 116, 133 (1998). See also Viscusi, supra note 121; ACKERMAN \& HEINZERLING, Priceless, supra note 23, at 79; Sidney A. SHAPIRO \& RoberT L. GLICKSMAN, Risk REGU. LATION At Risk: RESTORING A PRAgMATIC APPROACH 99-100 (2003).

124. Indeed, whether or not preferentialist in form, the reference case for defining and measuring welfare consequences of social choice tends to remain unequivocally focused on the status quo under CBA. See, e.g., U.S. Fish \& Wildlife SERV., Draft ECONOMIC ANALYSis of CRitical HABitat Designation For the Rio Grande Silvery Minnow, Final DRAFT (May 2002), cited in Amy Sinden, The Economics of Endangered Species: Why Less is More in the Economic Analysis of Critical Habitat Designations, 28 HARV. ENVTL. L. REV. 129, 169-170 ("The standard best practice in economic analysis is applying an approach that measures costs, benefits, and other impacts arising from a regulatory action against a baseline scenario of the world without the regulation.").

125. Cf. James M. Buchanan, Introduction: L.S.E. Cost Theory in Retrospect, in L.S.E. EsSAYS ON COST 1, 15 (James M. Buchanan \& G.F. Thirlby eds., 1981) ("[T]he opportunity cost involved in choice cannot be observed and objectified and, more importantly, it cannot be measured in such a way as to allow comparisons over wholly different choice settings.").

126. See SPASH, supra note 119, at 170-171 (describing William D. NORDHAUs, NEW ESTIMATES OF THE ECONOMICS IMPACTS OF CLIMATE CHANGE (1998)).

127. See infra text accompanying note 179. 
ject all but impossible. Moreover, it may well be that public policy choices of a certain scale or normative significance simply exceed the capabilities of CBA's methodological individualism. That is, just as certain attributes and behaviors of complex, adaptive biophysical systems cannot be predicted by examining individual system components alone, certain values and aims of the "social organism" 128 might not be capable of being identified or predicted through the simple aggregation of atomized preferences or interests. $^{129}$ Instead, those values and aims might in part emerge through the operation of social institutions and procedures themselves. As Laurence Tribe observes, "the whole point of personal or social choice in many situations is not to implement a given system of values in light of the perceived facts, but rather to define, and sometimes deliberately to reshape, the values-and hence the identity — of the individual or community that is engaged in the process of choosing." 130

Collective procedures of this nature tend to be seen as illiberal or paternalistic. It is true, of course, that "[i]f regulators reject people's actual judgments, then they are insulting their dignity."131 Yet there is also insult in attributing meaning and significance to behavior that individuals themselves may not desire or intend. For many pressing environmental and risk regulation issues, individual preferences are likely to be non-existent or ill-formed in the absence of an appropriate forum for discussing and determining social goals. For instance, simply toting up the "revealed" preferences of individuals regarding the myriad potential consequences of cloning livestock for human consumption ${ }^{132}$ seems, at least at present, to be a contrived exercise. We will not know our preferences with respect to cloned livestock unless and until we have a body of relevant experience from which to draw upon in our evaluations. Such experience will only occur with the prior consent

128. Id.

129. Consider, for instance, the finding that individuals are willing to trade off the absolute number of lives saved by a program in favor of the proportion of lives saved from some identified reference group. See Karen E. Jenni \& Geoge F. Loewenstein, Explaining the Identifiable Victim Effect, 14 J. OF RISK AND UNCERTAINTY 235, 254 (1997) [hereinafter Jenni \& Loewenstein, Explaining]. Researchers typically describe such findings as evidence of cognitive "bias" or error on the part of subjects. A more sympathetic interpretation, however, is that the introduction of reference groups into the experimental design provides subjects with an avenue-however thinly specified-for expressing the variety of sociallyinflected concerns that pervade risk regulation and that render simple body-counting exercises hopelessly artificial.

130. Laurence H. Tribe, Policy Science: Analysis or Ideology?, 2 PHIL. \& PUB. AFF. 66, 99 (1972).

131. Sunstein, Cost-Benefit Analysis and the Environment, supra note 35, at 24 (emphasis added).

132. See supra text accompanying note 71 . 
of our political community, whether actively or passively granted. Thus, except perhaps as a method of curtailing collective debate, it makes little sense at present to hinge policies regarding cloned livestock on our assumed preferences.

This potential deliberative deficit of preferentialism is also evident in Judge Posner's recent use of CBA to suggest that the optimal post-Katrina reconstruction plan for New Orleans is one in which "the historic portions of the city (the French Quarter and the Garden District) might be rebuilt and preserved as a tourist site, much like Colonial Williamsburg, without having to be part of a city." 133 Posner may well be right that the United States should not spend billions of dollars reconstructing New Orleans to its former scale, especially in light of projected sea level rises over the next century from climate change that would transform the city into an island. But the reason for this conclusion is not to be found in a CBA premised on the decontextualized preferences of individuals. Whatever pre-Katrina tourist behavior might suggest (for it is their disposable dollars that presumably are driving the conclusion that only the French Quarter and the Garden District are worth rebuilding), it is an open question whether individuals postKatrina agree that they have little use for a revival of the Ninth Ward and other poor, racially-segregated areas of the city. To say nothing of the deeper issues of environmental justice raised by the Katrina tragedy, we understate the role of citizenship when we assume that shared experiences do not affect the preferences that we hold and the meanings that we attribute to our social world.

\section{B. Membership}

In addition to embracing a view of social choice as merely the aggregation of existing individual interests, CBA also begins with the assumption that all relevant interest-holders have been identified for purposes of aggregation. In many instances, however, environmental policymaking will be concerned precisely with determining which interest-holders are entitled to membership in the political community, and on what basis their interests are to be considered. ${ }^{134}$ One long-recognized example concerns the selection of an appropriate stance toward animals and other non-human life

133. Richard A. Posner, Katrina, Cost-Benefit Analysis, and Terrorism, The BeckerPosner Blog, Sept. 4, 2005, available at http://www.becker-posner-blog.com/archives/ 2005/ 09/katrina_cost-be.html.

134. See Michael Walzer, Spheres of Justice: A Defense of Pluralism and EQUALITY (1983). 
forms. ${ }^{135}$ As this Section explains, certain other categories of interest-holders that are of special concern to environmental policymaking-including statistical victims, non-nationals, and members of future generations-find themselves ignored or devalued by the CBA procedure. To be clear, this is not to say that the precautionary approach provides more clear or appropriate guidance as to how to resolve the ethical and political issues raised by these missing interest-holders. The PP approach does, however, explicitly recognize the need for development of new norms of national, global, and intergenerational environmental responsibility. In contrast, CBA seems to offer the implicit message that our intellectual needs consist only of better data and more rigorous techniques of valuation. ${ }^{136}$

CBA's deficits in this regards are well demonstrated by the procedure's treatment of consent to environmental risks. As noted above, CBA proponents often view labor market revealed preference studies as a sufficient basis for assuming individualized consent to the imposition of all manner of health and safety risks, a belief that in turn leads them to argue that CBA does not involve human life or health at all, but instead only the "monetary equivalents" of such values. ${ }^{137}$ To the extent that they recognize the analytical leap implicit in this argument, proponents of CBA defend the leap by noting that most human health risks from environmental hazards are quite small and, thus, officials can assume that individuals hypothetically would consent to the risks for a price comparable to the implicit value of life that is derived from the wage-risk premium literature. ${ }^{138}$ Not only does this defense fail to grapple with the fact that individual responses to even actuarially identical risks vary dramatically based on the risks' qualitative characteristics, ${ }^{139}$ but it also ignores the fact that a variety of adverse health risks associated with pollution and other hazards are not trivially small. ${ }^{140}$ To abstract away from such qualitative

135. See generally Animal Rights: CuRREnt Debates AND New DiRECTIONs (Cass R Sunstein \& Martha C. Nussbaum eds., 2004).

136. See Lisa Heinzerling, Knowing Killing and Environmental Law, 14 N.Y.U. ENVTL. L. J. 521 (2006).

137. See Eric A. Posner \& Cass R. Sunstein, Dollars and Death, 72 U. CHI. L. REV. 537, 538 (2005).

138. See Sunstein, Cost-Benefit Analysis and the Environment, supra note 35, at 25 ("In many cases of environmental regulation . . . rights violations are not involved; we are speaking here of statistically small risks.”).

139. For a recent and probing survey of issues related to the project of better "individuating" monetary values of statistical lives, see Cass R. Sunstein, Valuing Life: A Plea for Disaggregation, 54 DUKE L. J. 385 (2004).

140. See, e.g., Anne Rajotte, Asthma and Pesticides in Public Schools: Does the ADA Provide a Remedy Where FIFRA Fails to Protect?, 31 B.C. ENVTL. AFF. L. REV. 149, 153 (2004) (noting that childhood asthma rates have doubled over the past century, with 4.8 
and quantitative features of risk in search of a uniform clearing price for life risks understating the profundity of collective decisionmaking regarding institutionalized harm.

CBA's limitations in this regard again seem to be driven by the procedure's purely individualistic conception of value. Without an identity - and therefore without a willingness or even an ability to pay for protection-those lives that are threatened by statistical risks seem not to represent human lives at all. Statistical risks, however, represent "none of us" and "all of us" at once. ${ }^{141}$ Because CBA refuses to see "all of us" as an interest-holder, it is incapable of treating environmental, health, and safety regulation with the moral richness that the subject deserves. As Lisa Heinzerling notes, by pricing human life and sanctioning actions that place it in jeopardy in advance of their occurrence, "the most basic kind of right-the right to be protected from physical harm caused by other people, on equal terms with other people-is denied to those whose lives are framed in statistical terms." 142 Rather than begin with a wholesale level of presumed consent to the imposition of risk, the $\mathrm{PP}$ instead begins with a strong entitlement to bodily integrity and ecological support, and a corresponding duty on the part of others to avoid causing serious or irreparable harm to those interests. Difficult questions of implementation and exception are immediately raised, but the baseline normative condition under the PP remains one of sanctity for human life, not vulnerability.

A similar tenuousness characterizes the position of nonnationals and other currently living individuals who stand outside of the particular political community that engages in a CBA policymaking exercise. After all, one cannot readily conduct a CBA to determine whether and how the interests of such individuals

million children presently affected, and that "[e]nvironmentally-related exacerbation is estimated to account for one third of childhood asthma cases").

141. See Mari Matsuda, On Causation, 100 ColuM. L. REv. 2195 (2000); Keating, Pricelessness, supra note 23, at 174-75.

142. Lisa Heinzerling, The Rights of Statistical People, 24 HARV. ENVTL. L. REV. 189, 189-90 (2000). See also Frank I. Michelman, Pollution as a Tort: A Non-Accidental Perspective on Calabresi's Costs, 80 YALE L. J. 547 (1971). Psychologists uncover a similar disparity in the intuitive reactions of subjects to manipulations of the perceived "identifiability" of victims aided by policy proposals, see Deborah A. Small \& George Loewenstein, Helping " $a$ " Victim or Helping "the" Victim: Altruism and Identifiability, 26 J. OF RISK AND UNCERTAINTY 5 (2003), a finding related to the "reference group" effect describe above. See Jenni \& Loewenstein, Explaining, supra note 129. Shi-Ling Hsu argues that this effect may be countered by the optimizing procedure of CBA, which specifically avoids hinging policy decisions on features of identity and agency. See Shi-Ling Hsu, The Identifiability Bias in Environmental Law (2005) (unpublished manuscript, on file with the author). As noted infra text accompanying notes 211-225, however, complete erasure of human identity and agency introduces its own undesirable distortions, the long-term cost of which may be literally incalculable, in the sense that it involves an impairment of our ability to coherently reason about-and to calculate- the moral implications of human behavior. 
should be counted for purposes of conducting CBA. ${ }^{143}$ Yet a great deal of environmental policymaking and the pursuit of sustainable development is bound up precisely with the challenge of perceiving and respecting the interests of globally dispersed populationspopulations that, despite their political dispersion, nonetheless share elaborate networks of ecological and economic interdependence. ${ }^{144}$ Increasingly, individuals are being asked by international environmental norm entrepreneurs to express regard and concern for the social and environmental conditions of other nations in their purchasing and other private decisionmaking. ${ }^{145}$ The nationstate, however, remains the critical geopolitical actor for most of environmental law and regulation and, thus, any policy framework such as CBA that does not resolve how to address extrajurisdictional effects cannot be regarded as a comprehensive solution to environmental policymaking. ${ }^{146}$

Finally, and most importantly, CBA's framework struggles to acknowledge future generations as interest-holders in themselves, rather than merely as objects of valuation by the presently living. Scholars have long acknowledged the theoretical difficulties presented by the topic of intergenerational justice, ${ }^{147}$ many of which arise again from the fact that our bedrock normative theories tend to be liberal-individualistic in form. Like children, future generations are part of the "Achilles' heel" of liberalism"148_that vulnerable location for interest holders who are imperfectly situ-

143. See Eric A. Posner \& Alan O. Sykes, An Economic Analysis of State and Individual Responsibility Under International Law (Univ. Chicago Law \& Econ., Olin Working Paper No. 279, Stanford Law and Economics Olin Working Paper No. 318, 2006), available at http://papers.ssrn.com/sol3/papers.cfm?abstract_id=885197.

144. See, e.g., Thomas Pogge, REalizing RaWls 8-9 (1989) ("The effects of my conduct reverberate throughout the world, intermingling with the effects of the conduct of billions of other human beings .... We as individuals have no hope of coping with such complexity and interdependence if we take the existing ground rules for granted and merely ask 'How should I act?"').

145. See Kysar, Preferences for Processes, supra note 51.

146. Compare Exec. Order No. 12114, Environmental Effects Abroad of Major Federal Actions, Jan. 4, 1979 (requiring federal agencies to develop procedures for evaluating major federal actions that have significant extraterritorial environmental effects).

147. See, e.g., Bruce A. ACKERMAN, Social Justice in the Liberal STATE 202 (1980) (observing that the "problem of inheritance is of such great theoretical importance that we must confront it head-on if we hope to grasp the shape of liberal ideals"); DEREK PARFIT, REASONS AND PERSONS 351 (1984) (developing norms of intergenerational responsibility "is the most important part of our moral theory, since the next few centuries will be the most important in human history"); JOHN RAWLS, A THEORY OF JUSTICE 284 (1971) (observing that "the question of justice between generations . . . subjects any ethical theory to severe if not impossible tests"); Amartya K. Sen, On Optimising the Rate of Savings, 71 ECON. J. 479, 486 (1961) (observing that there can be no democratic solution to intergenerational problems); Lawrence B. Solum, To Our Children's Children's Children: The Problems of Intergenerational Ethics, 35 LOY. L.A. L. REV. 163, 164 (2001) ("The problems of interegenerational ethics are notoriously some of the most difficult in moral and political philosophy.").

148. Steven Shiffrin, Government Speech, 27 UCLA L. REV. 565, 647 (1980). 
ated to identify and assert their rights or interests in the manner that liberalism demands of them. Future generations are especially burdened in this regard, for not only are they non-existent, but they also are cognitively obscured even to those presently living, given liberalism's tendency to adopt one or another form of methodological individualism.

These limitations are well-demonstrated by what Derek Parfit has termed the non-identity problem: the fact that whatever policy is selected for a given issue may affect the very identity of future individuals. ${ }^{149}$ The non-identity problem is related to, but distinct from, the problem of endogenous preferences, in which environmental policy is recognized to have profound effects on the preferences of individuals (including even those previously identified preferences that may have been used to determine the content of environmental policy). ${ }^{150}$ In the intergenerational context, the problem is not merely that individuals' preferences shift as a result of policy choices, but that their very existence is made contingent on our choices. In such circumstances, we cannot say that future individuals will be made better or worse off by a policy choice, only that they will be made.

To the student of complexity theory, this problem of contingent identity is quickly recognized as a manifestation of the profound endogeneity and interconnectedness of complex adaptive systems; to the cost-benefit analyst, on the other hand, the problem appears fundamentally disruptive. Indeed, as Parfit notes, the non-identity problem poses deep conceptual challenges to any theory of normative ethics that is framed in terms of the rights, preferences, or interests of particular individuals. ${ }^{151}$ Such "personaffecting" normative theories provide little analytical traction in decisionmaking contexts where the relevant consequences will be felt by entirely different persons depending on how the decision is resolved. As a result, our moral thinking regarding such dilemmas is at present highly immature. It has, for instance, led to the con-

149. See PARFIt, Reasons AND Persons, supra note 147. See also Anthony D'Amato, Do We Owe a Duty to Future Generations to Preserve the Global Environment?, 84 AM. J. INT'L L. 190 (1990); Edith Brown Weiss, Our Rights and Obligations to Future Generations for the Environment, 84 AM. J. INT'L L. 198 (1990).

150. See Mark Sagoff, The Economy of the Earth: Philoposhy, LaW and The ENVIRONMENT 63 (1988) (observing that "[o]ur decisions concerning the environment will . . . determine, to a large extent, what future people are like and what their preferences and tastes will be"); Talbot Page, On the Problem of Achieving Efficiency and Equity, Intergenerationally, 73 LAND ECON. 580, 591 (1997) ("How well the resource base is kept intacthow diminished it will be in biological diversity, how depleted in its soils, forests, groundwater, how crowded in population-will shape our grandchildren's prospects and values and in doing so will shape intergenerational society.").

151. See PARFIT, REASONS AND PERSONS, supra note 147, at 370-71. 
clusions that we have no obligations to future generations whatsoever, ${ }^{152}$ or that we have only an obligation to ensure that our choices leave future generations with lives that are minimally worth living. ${ }^{153}$

In order to avoid such unattractive conclusions, Parfit argues that we need to move beyond simple "appeal to what is good or bad for those people whom our acts affect," and instead to begin developing methods of evaluating "different sets of possible lives."154 In the intergenerational environmental context, one promising mechanism for doing so is to conceive of the "communities which future people belong to [as] deserving of concern and respect in their own right." 155 As discussed in Part III, the PP promotes just such a conception by establishing a standard of agentrelative environmental responsibility, in which human societies and generations are seen as distinct moral agents that stand in relations of responsibility and indebtedness to each other. Through such a partial concession to communitarianism, we can begin to harmonize our liberal individualistic ideals with the reality that some measure of paternalism and coercion is simply inescapable vis a vis future generations and other members of liberalism's Achilles' Heal.

CBA proponents instead try to address this dilemma through the use of an elaborate mathematical tool-the discount rate. Although a full discussion of the use of discounting in the intergenerational policy context is beyond the scope of this Article, ${ }^{156}$ the practice does deserve brief mention because the effect of discounting future costs and benefits to a present value tends to swamp all other variables within long-term CBA. ${ }^{157}$ Of the various normative justifications that have been offered for the use of discounting, the most substantively significant is based on the idea that, unless future costs and benefits are discounted according to a rate that reflects the return on investment offered by alternative uses of public funds, society will fail to maximize its welfare over

152. See S.A. Marglin, The Social Rate of Discount and the Optimal Return of Investment, 77 Q. J. ECON. 97 (1963).

153. See T. Schwartz, Obligations to Posterity, in Obligation to Future GeneraTIONS (R.I. Sikora \& Brian Barry eds., 1978).

154. See PARFIT, REASONS AND PERSONS, supra note 147, at 377-78.

155. E. Page, Global Warming and the Non-Identity Problem, in SELF AND FUTURE Generations: An InTERCultural CONVERSATION 107, 123 (T.C. Kim \& R. Harrison eds., 1999) (emphasis omitted).

156. For an overview of the discounting debate and an argument that discounting in the intergenerational policy context lacks a coherent normative justification, see Douglas A. Kysar, Discounting, On Stilts, 74 U. CHI. L. REV. _ (forthcoming 2007) [hereinafter Kysar, Discounting].

157. See SPASH, supra note 119. 
time. Thus, the reduction of future consequences to a present value is thought to ensure that policymakers will remain mindful of the opportunity costs of regulation, a practice that is said to be temporally neutral because it leads to the overall maximization of social welfare, regardless of how that welfare happens to be distributed across time.

This conventional justification for the use of discounting within CBA falters when policymaking includes significant intergenerational effects, for the very values that are to be discounted depend on the specification of a background distribution of rights and responsibilities across generations. Much of environmental law and policy can be thought of as concerned directly with the establishment of that background distribution. ${ }^{158}$ Thus, we should be skeptical of the contention that "the debate over [intergenerational equity] should be separated from the debate over discounting," 159 given that the latter so heavily depends on the former. Through discounting, the fundamental issue of intergenerational equity - which risks and resources, as an ethical matter, should be imposed or bestowed on future generations?-is conflated with the issue of intergenerational efficiency-which generation, as a technical matter based on a given rate of discount and distribution of resource entitlements, does or will derive more utility from the use of a given resource? Future generations, in essence, are forced to "outbid" present owners by an amount reflecting not only the strength of their needs, but also the alternative uses to which all resources-including the "monetary equivalents" of their own livescould be put during the intervening time periods.

\section{Discursive Rationality}

As noted above, ${ }^{160}$ the contention of PP proponents that environmental, health, and safety decisionmaking is characterized by abiding uncertainty does not commit them to the extreme conservatism of the maximin approach as a general or permanent response. Rather, the PP is intended to commence a program of risk regulation that is both proportionate to the scope of the perceived threat and capable of being updated and adjusted over time. Proponents of the safe minimum standards approach within environmental economics also tend to qualify their position, arguing that

158. See Kysar, Discounting, supra note 156.

159. Cass R. Sunstein \& Arden Rowell, On Discounting Regulatory Benefits: Risk, Money, and Intergenerational Equity, 74 UNIV. CHI. L. REV._(forthcoming 2007) (manuscript at 22 , on file with author).

160. See supra text accompanying notes $37-38$. 
fidelity to safe minimum standards should yield when the costs of precaution become "immoderate"161 or "unacceptably large."162 Within the legal literature, Dan Farber similarly allows for departure from his strong "environmental baseline" approach to policymaking "when costs would clearly overwhelm any potential benefits" from precautionary regulation. ${ }^{163}$

Although critics sometimes argue that these various safety valves suggest a latent efficiency criterion within the precautionary approach, ${ }^{164}$ there are important distinctions that prevent the $\mathrm{PP}$ from collapsing into CBA, even granting the addition of some form of cost sensitivity. To begin with, the PP's understanding of cost is much broader than the notion presupposed by CBA. ${ }^{165}$ As Bishop wrote in a seminal article on the safe minimum standards approach to endangered species protection, the determination of "[h]ow much [cost] is 'unacceptably large' must necessarily involve more than economic analysis, because endangered species involve issues of intergenerational equity." 166 Similarly, advocates of the $\mathrm{PP}$ typically contemplate an inclusive process for making determinations about how to apply the principle, suggesting that the decision to relax its dictates can and should be premised on a range of appropriate reasons beyond simply welfare-maximization. ${ }^{167}$ Given the ethical implications of such determinations, PP proponents are simply unwilling to replace considered, democratic judgments with mechanical devices such as risk aversion or option value premiums. Instead, such judgments are seen as unavoidably contingent and case-specific. ${ }^{168}$

161. Ciriacy-Wantrup, supra note 103, at 252.

162. R.C. Bishop, Endangered Species and Uncertainty: The Economics of a Safe Minimum Standard, 60 J. AM. AG. ECON. 10, 13 (1978). Bishop clearly incorporates sensitivity to opportunity costs in his temperance of the safe minimum standards approach: "To get at total social costs [of implementing the safe minimum standard], any measurable benefits of conservation efforts must be subtracted from out-of-pocket and opportunity costs." R.C. Bishop, Endangered Species: An Economic Perspective, quoted in Tom W. Crowards, Safe Minimum Standards: Costs and Opportunities, 25 Ecol. ECON. 303, 304 (1998).

163. See Daniel A. Farber, Ecopragmatism: Making Sensible Environmental DECISIONS IN AN UNCERTAIN WORLD 201 (1999).

164. See, e.g., J. Rolfe, Ulysses Revisited-A Closer Look at the Safe Minimum Standard, 39 AUSTRALIAN J. AG. ECON. 55 (1995).

165. See Communication from the Commission, supra note 37, at 19 ("Examination of the pros and cons cannot be reduced to an economic cost-benefit analysis. It is wider in scope and includes non-economics considerations.").

166. Bishop, supra note 162, at 10.

167. See, e.g., Nicholas Ashford et al., Wingspread Statement on the Precautionary Principle (1998), available at http://www.gdrc.org/u-gov/precaution-3.html ("The process of applying the Precautionary Principle must be open, informed and democratic and must include potentially affected parties.”).

168. Cf. Case T-13/99, Pfizer Animal Health S.A. v. Council, 2002 E.C.R. II-3305, ๆ 160-61 (describing application of the PP as a "balancing exercise" that depends on "the particular circumstances of each individual case"). 
Even if mechanical devices of the kind sought by CBA proponents could be identified, the cost-benefit procedure still would fail to register the sense of regret that accompanies risk regulation's tragic choices and that compels more searching inspection of how to design a society in which such choices are not as starkly and pervasively posed. ${ }^{169}$ Lives lost under the "do the best you can" heuristic and other precautionary approaches are not viewed as efficient "tradeoffs," accepted in exchange for whatever utility has been gained. Instead, they are viewed as tragic, regrettable consequences of human fallibility and finitude-a "moral remainder"170 that provides enduring motivation for surviving members of society to seek ways of doing better in the future. In contrast, because it aspires to comprehensive rationality, CBA must invariably round this moral remainder to zero. In the process, it must also fail to encourage an appropriate degree of collective self-awareness regarding the deep normativity of risk regulation.

A key benefit of the PP, therefore, is that it contains a builtin sensitivity to the need for collective deliberation. Even if we know that the PP's more severe implications will need to be relaxed, the principle nevertheless forces societal discussion regarding the normative status of statistical victims, other societies, and future generations. ${ }^{171}$ In that regard, the PP's insistence that human health and the environment deserve constant, anticipatory attention serves as a procedural lever for furthering still-nascent attempts to reason through important questions that lie at the "frontiers of justice"-questions about our responsibilities to members of other nations, other generations, and other species. ${ }^{172}$ Such an approach therefore aspires not only to be procedurally rational (e.g., in the sense that dynamic, incremental management approaches are demanded in the face of complexity and uncertainty in biophysical and sociolegal systems ${ }^{173}$ ), but also to be discursively rational (e.g., in the sense that the PP helps to structure and promote collective deliberation regarding decisions for which our ex-

169. See Martha C. Nussbaum, The Costs of Tragedy: Some Moral Limits of CostBenefit Analysis, 29 J. LEGAL STUD. 169 (2000).

170. Daniel Markovits, Legal Ethics and the Lawyer's Point of View, 15 YALE J.L. \& Human. 209, 231. See also Guido CALABREsi \& Philip BobBit, Tragic Choices 32 (1978) (referring to "the costs of costing" as "the external costs . . of market determinations that say or imply that the value of a life or of some precious activity integral to life is reducible to a money figure").

171. Cameron, supra note 41, at 292 (arguing that the PP, "by explicitly noting the limits of scientific determination, ... legitimates public political determination [of risk regulation issues]").

172. Cf. Martha C. Nussbaum, Frontiers of Justice: Disability, Nationality, SPECIES MEMBERSHIP (2006).

173. See supra text accompanying notes 109-117. 
isting, individualized preferences are either ill-formed or ill-suited for the decision under inspection).

Of course, the PP's desire to encourage inclusive and robust deliberation may not easily comport with its desire to allow flexible, dynamic regulatory processes. As J.B. Ruhl has observed, adaptive management may well be inconsistent with traditional administrative law mechanisms for ensuring robust public participation in regulatory decisionmaking. ${ }^{174}$ Moreover, some proponents of adaptive management appear to envision an expansive normative role for the experts who are placed in charge of ecosystem management. ${ }^{175}$ Thus, whether by dint of a mismatch between adaptive management and the cumbersome processes of public participation, or by dint of an increasing willingness among experts to inject their normative views into the management process itself, the goals of procedural and discursive rationality may well be in tension with each other, even on the more populistoriented precautionary approach. A critical task for environmental law going forward, therefore, will be to identify an appropriate division of labor between expert adaptive managers and the broader political community that enlists their aid in the pursuit of sustainable development.

\section{The Problem of AgenCy}

At bottom, the distinction between CBA and the PP reflects a distinction between agent-neutral and agent-relative conceptions of risk regulation. CBA aspires to achieve complete agentneutrality at the level of the political community by disclaiming

174. See J.B. Ruhl, Regulation By Adaptive Management: Is It Possible?, 7 MinN. J. L. SCI. \& TECH. 21 (2005).

175. That is, recognizing that human values, choices, and activities inevitably impact the objects of their study, they contend that "the notion of a pristine objective scientific observer, is not applicable to the study of self-organising systems." James Kay \& Eric Schneider, Embracing Complexity, The Challenge of the Ecosystem Approach, in PERSPECTIVES ON ECOLOGICAL INTEGRITY 49 (L. Westra \& J. Lemons, eds. 1994). Instead, they argue that scientists should take deliberately normative positions with respect to those human values, choices, and activities that impact ecosystem integrity. See, e.g., G.K. Meffe \& S. Viederman, Combining Science and Policy in Conservation Biology, 23 WILDLIFE Society Bulletin 327 (1995) ("Scientists can take a clear stand that biodiversity is good, that functioning and intact ecosystems are good, that continued evolutionary change and adaptation are good, and that diversity and variation in general is good. Scientists cannot and should not remove themselves from these usually unstated value judgments."). Others argue that the fact-value distinction, however philosophically troubled, must remain nominally intact in order to safekeep the professional authority and deference traditionally accorded to scientists. See R.T. Lackey, Seven Pillars of Ecosystem Management, 40 LANDSCAPE \& URBAN PLANNING 21, 25 (1998) ("Ecosystem management should maintain ecosystems in the appropriate condition to achieve desired social benefits; the desired social benefits are defined by society, not scientists."). 
the relevance of any normative considerations beyond the welfare impacts of regulatory decisions on individual members of the community. Collective values or aims, in other words, play no role in the CBA exercise, apart from the foundational choice to fix collective decisionmaking upon the aggregation of individual welfare consequences. As Parts I and II demonstrate, however, CBA must resort to controversial assumptions and exclusions in order to maintain the perception that discretionary choices are not being made within its framework.

As an indication of the degree of confusion in this area, some CBA proponents attempt to deny that individual welfare maximization is a moral choice at all. They state, for instance, that their analysis of "risk equity will not be from the standpoint of moral criteria but rather social welfare maximization."176 Similarly, they express a belief that "the moral debates" over discounting in the intergenerational policy context can be bracketed by "investigating people's actual preferences in this domain." 177 The analyst wants to reassure observers that CBA consists of a "technical" and "objective" task of identifying and tabulating welfare consequences of policymaking, but any effort to actually define, construct, and implement a social welfare function entails extraordinarily difficult normative-and political-judgments. After all, the dichotomy of fairness versus welfare only arises after the analyst has first defined welfare using criteria of justice . . . and fairness. ${ }^{178}$

These are familiar debates. As this Part observes, however, there is an even more fundamental problem with CBA's attempt to disclaim its own normativity. By analogizing from the metaethical construction of individual moral agency, this Part suggests that CBA's project may ultimately be self-undermining in that it serves to erase the kinds of conceptual distinctions that are necessary in order to preserve the sense that a political community should engage in decisionmaking of any sort. That is, because an essential premise of CBA is that collective choice should passively and impartially trace the results of an individualized welfare calculus, government policies on the CBA account are not attached to any identifiable agent who bears responsibility for their content or effect. Ultimately, this attempt to "regulate from nowhere" may be just as tenuous and self-defeating as moral philosophers have deemed the attempt to fix individual decisionmaking solely on an

176. Viscusi, Risk Equity, supra note 121, at 844.

177. Sunstein \& Rowell, supra note 159, manuscript at 5.

178. Compare LOUIS KAPLOW \& STEVEn SHAVELL, FAIRNESS VERSUS WELFARE (2002). 
impartial assessment of consequences. ${ }^{179}$ In both contexts, the attempt to eliminate discretion through a formalized choice calculus inadvertently risks eliminating the basis on which the deciding agent has come to view the choice-making context as significant, as somehow worthy of governing criteria of any sort.

The PP, in contrast, offers a simple but meaningful acknowledgment both of the distinctiveness of political communities and of the overwhelming challenge of guiding their collective choices within a world of complexity, uncertainty, and interdependency between human individuals, societies, and generations. As will be argued, the PP's apparent qualitative distinction between risks imposed and benefits foregone does not represent an inexcusable ignorance of opportunity costs, as critics claim, but rather a subtle reminder that public policymaking is at bottom an act of collective responsibility. As argued in Parts I and II, the CBA paradigm struggles to address many of the central questions raised by the sustainable development challenge, including most significantly the need to further our moral thinking concerning those interest holders who do not enter smoothly into conventional liberal frameworks. Thus, the PP's deliberate attempt to "get the social organism thinking" 180 may be desirable simply as a way of promoting the development of new norms of global and intergenerational environmental responsibility at a time when such development is sorely needed.

\section{A. Partiality}

The impartialist command of consequentialist-utilitarianism, which prescribes utility-maximizing behavior for individuals irrespective of whether the utility flows to their benefit or to others', has long been regarded as practically unlivable, however laudable its aim. The command also has long been regarded as conceptually problematic, in that it seems difficult to square a coherent, stable conception of individual agency with a normative ethical theory that denies the distinctiveness of any such agency. In other words, by forcing the individual to regard her actions as fundamentally mundane, in the sense that they are qualitatively indistinguishable from her omissions and, indeed, from all other causal forces, the impartialist command also seems to force her to

179. See Douglas A. Kysar \& Ya-Wei Li, Regulating from Nowhere: Domestic Environmental Law and the Nation-State Subject, in Globalization Comes Home: How the United States is Being Transformed by Globalization (Beverly Crawford \& Michelle Bertho, eds., forthcoming 2007).

180. Louis Menand, The Metaphysical Club 299 (2001) (quoting letter from John Dewey). 
abandon the notion that her actions in any sense matter. Part of the reason for the cognitive attractiveness of agent-relative theories of individual ethics, then, lies in their ability to prevent our lives and our identities from receding entirely into the broader causal systems within which we are undoubtedly situated. As Bernard Williams famously argued, attaching some special moral significance to the affirmative expressions of an individual's particular agency enables the person to be "identified with his actions as flowing from projects and attitudes which in some cases he takes seriously at the deepest level, as what his life is about . . ."181

Complexity theory underscores the importance of this function by positing an expansive, yet simultaneously imperfect causal potential on the part of any single component within complex, adaptive systems. The challenge of crafting a moral identity within such a "complicated tissue of events" 182 is especially profound: Not only does the individual face innumerable opportunities to act, but she also experiences her actions as deeply embedded within a causal order that belies the classical liberal belief in predictable dyadic causal relations. ${ }^{183}$ Accordingly, under a duty of impartial optimization, the poet's "saddest" category-what "might have been"- becomes much more than simply a reflective indication of the challenge of crafting an identity in a world of indefinitely many causal opportunities. Instead, it becomes a reflexive imperative to act and choose in a manner that draws no boundaries between the human actor and the complex causal system within which she is situated. For this reason, deontologists hold onto much-maligned conceptions such as the act-omission distinction. Despite being endlessly manipulable ${ }^{184}$ and seemingly tolerant of unacceptable results in particular cases, ${ }^{185}$ such distinctions ultimately help to preserve a coherent, stable conception of individual moral agency.

Consequentialist-utilitarians, on the other hand, regard the act-omission distinction and other familiar manifestations of agent-relative ethics as evidence of cognitive "bias"186 that should

181. Bernard Williams, A Critique of Utilitarianism, in ETHICS: History, THEORY, AND ConTEMPORARY Issues 567, 582 (Steven M. Cahn \& Peter Markie eds., 1998).

182. WERnER HEISENBERG, PHYSICS AND PHILOSOPHY 96 (1958).

183. Cf. Mark Kelman, The Necessary Myth of Objective Causation Judgments in Liberal Political Theory, 63 CHI.-KenT L. REv. 579 (1987) (describing the inability of dominant liberal political theories to account for problems of indeterminacy in establishing causal relations).

184. See Mark Kelman, Taking Takings Seriously: An Essay for Centrists, 74 CAL. L. REv. 1829 (1986) [hereinafter Kelman, Taking Takings Seriously].

185. See Peter Singer, Famine, Affluence, Morality, 1 PHIL. \& Pub. AfF. 229 (1972).

186. See Robert A. Prentice \& Jonathan J. Koehler, A Normality Bias in Legal Decisionmaking, 88 CORNELL L. REV. 583, 587 (2003) (describing the "omission bias" as "the tendency of people to find more blameworthy bad results that stem from actions than bad results that stem from otherwise equivalent omissions"); Laura Y. Niedermayer \& Gretchen 
be "escape[d]."187 In a recent lecture, for instance, Cass Sunstein speculates that the deontological moral tradition-particularly as it is expressed in such principles as the prohibition on affirmatively acting to cause a loss of human life-arises not from a fullfledged, independent philosophical framework, but from the use of "moral heuristics ... or rules of thumb, that work well most of the time, but that also systematically misfire." 188 And, indeed, Sunstein believes that the Kantian prohibition on knowingly taking innocent human life misfires, "at least [when] the deaths are relatively few and an unintended byproduct of generally desirable activity." 189 Instead, he argues that the normativity of action should be determined by a full and impartial evaluation of its expected consequences on relevant interest-holders.

As Samuel Scheffler has explained, however, a normative standard of "instrumental optimality" for individuals-which attaches no special significance to the actions, interests, or other features of the agent herself-must derive its moral attraction, paradoxically, from "considerations other than instrumental optimality." 190 The contrary notion that instrumental optimality has primary normative significance faces inescapable complications. For instance, as decision theorists have demonstrated, there may be circumstances in which the deliberate attempt to optimize may not be the most sure route to optimization. ${ }^{191}$ Knowing when and how

B. Chapman, Action, Inaction, and Factors Influencing Perceived Decisionmaking, $14 \mathrm{~J}$. BeHAV. DECISIONMAKING 295, 296 (2001) (defining the bias as "the tendency to judge actions as worse than omissions when they both have the same bad consequences"). Psychologists argue that the act-omission distinction reflects a cognitive bias because "[p]eople continue to distinguish acts and omissions ... . even when the feature that typically makes them different is absent." Jonathan Baron, Nonconsequentialist Decisions, 17 BEHAV. \& BRAIN Sci. 1, 3 (1994). Researchers argue, for instance, that the act-omission distinction arises from individuals' tendency to perceive acts as more purposeful or intentional, and thus more blameworthy, than omissions. Accordingly, they regard observed behavior as biased or overgeneralized if subjects continue to exhibit an act-omission distinction even when experimenters manipulate perceived intentionality. See KeITH E. STANOVICH, Who Is RATIONAL?: STUDIES OF INDIVIDUAL DIFFERENCES IN REASONING 195 (1999). As this Section argues, however, the distinction between acts and omissions for purposes of moral reasoning is far more basic than the omission bias literature appreciates, related as it is to the very notion of agency that grounds such reasoning. Experimental manipulation of intentionality or other presumed components of the distinction therefore should not be expected to lead to its complete erasure.

187. Jonathan Baert Wiener, Beyond the Balance of Nature, 7 DuKE EnVTL. L. \& POL'Y F. 1, 16-17 (1996).

188. Cass R. Sunstein, Moral Heuristics and Moral Framing, 88 MinN. L. REV. 1556, 1558 (2004).

189. Id. at 1580 .

190. Samual Scheffler, Doing and Allowing 114 ETHICs 215, 232 (2004).

191. See Kysar et al., supra note 31 (arguing that psychologists and legal scholars have wrongly interpreted Herbert Simon's notion of bounded rationality to consist simply of optimization under informational and cognitive constraints, rather than a more nuanced notion in which heuristic, non-optimizing decisionmaking procedures are evaluated for their "ecological rationality" in light of the actual environments in which they are utilized). 
to depart from the optimization calculus in favor of more pragmatically sensible approaches therefore implies the existence of some independent agent responding to at least some additional normative criteria. Similarly, the desirability of holding oneself to a norm of instrumental optimality cannot be premised on a judgment that it is the instrumentally optimal thing to do- "if it did, one would need already to have accepted the norm in order to see oneself as having reason to accept it, which means that the proposed derivation is circular." 192 To avoid such circularity, one first must posit an independent human subject who views herself as peculiarly responsible for the affirmative expressions of her moral agency, in the sense that those expressions are guided by reasons that she herself has considered and chosen. That very brand of discretion, however, seems to be what impartial utilitarianism eliminates from our moral reasoning.

Scheffler's argument bears some relationship to Daniel Markovits's effort to construct an account of "the necessary architecture of the first person," in which Markovits argues that any meaningful conception of personal moral agency must include a recognition of oneself not only as an agent responsive to reasons for acting, but also as a generator of reasons, including reasons that are intimately and uniquely one's own. ${ }^{193}$ While Scheffler argues that the mere fact that individuals view themselves as subject to moral norms of any sort implies that they must accept a distinction between their agency and the larger causal order, Markovits argues that a minimal logical requirement of individuals being able to coherently view themselves as moral agents is an ability to supply reasons for acting that are not solely dictated by an external normative theory, such as the optimization rubric underlying CBA. From either perspective, the rub is that by urging a standard of agent-neutral utilitarianism, causal optimizers also implicitly ask us to deny the belief that our judgments and our actions are morally distinctive-the very belief that seems to be a minimally necessary precondition for having reason to accept any theory of normative ethics.

Defenders of optimization might respond that the conceptual "separateness" of moral agents is maintained in their framework by the fact that the utilitarian calculus takes account of an individual's own particular causal position and information set when calculating optimal courses of action. Optimizers, however, have no way of cabining their logic, for presumably individuals

192. Scheffler, supra note 190, at 232 .

193. Markovits, supra note 170, at 249. 
also should choose to position themselves within causal settings and to invest in obtaining information in a manner that is calculated to achieve optimal outcomes. ${ }^{194}$ Soon enough, this duty of causal optimality becomes infinitely self-referential, and the individual becomes lost within a framework that achieves its goal of consistent moral treatment only by denying the very basis on which individuals have come to think of themselves as distinct moral agents.

Indeed, the optimization framework is not only unhinged-in the sense that it exogenizes the process by which its intended audience develops and maintains a sense of personal urgency concerning the framework's subject matter-but it also is expressed in a formal language that implicitly condemns the discretion and judgment of its subjects. Like any other theory of normative ethics, optimization depends for its relevance and coherence on the existence of agents who are empowered to respond to reasons for acting, including at least some reasons for acting that are entirely independent of an externally imposed normative framework. ${ }^{195}$ Unlike theories of normative ethics that do not aspire to comprehensive rationality, however, the formal language of optimization by its very nature tends to disparage any such independent reasons for acting. That is, the formalized moral world of impartial optimization offers a series of stark choices: fairness versus welfare, precaution versus maximization, subjectivity versus rationality. Thus, although the optimization framework depends for its persuasiveness on the continued self-awareness and cognitive independence of the agents it seeks to persuade, its axiomatic structure simultaneously and unavoidably condemns those agents' independent judgment as leading to sub-optimal outcomes. Under such a conception, it is hard to imagine how individuals would continue to view themselves as distinctive moral actors who should abide any notions of virtue and responsibility.

\section{B. Collectivity}

Early domestic efforts to eliminate ozone-depleting substances in the United States were based largely on theoretical arguments as to their potential for harm, a classic example of pre-

194. Cf. infra text accompanying note 74 (describing a similar "optimal stopping problem" with respect to CBA and information costs).

195. See Markovits, supra note 170, at 227 (observing that consequentialism and other third-personal ethical theories fail to appreciate "the relation of authorship ... that a person has to his own actions, a relation the person does not have to other people's actions, not even to those that he could have prevented"). 
cautionary regulation in the face of incomplete information regarding potentially disastrous environmental harms. Years later, empirical investigations confirm the grounds of the scientific community's earlier concerns, and cost-benefit analyses now are capable of "verifying" the wisdom of that earlier precautionary action. Significantly, precautionary wisdom emerged at the time of that earlier action from a political body that saw itself as standing outside of, and being critically disposed toward, its tools of risk assessment and welfare maximization. ${ }^{196}$ Indeed, at the time that the United States led the global effort to reduce the use of ozone-depleting substances, computer programs were rejecting satellite data on the extent of loss in the ozone layer as being too far from the range of expected results to be valid. ${ }^{197}$

Today, the precautionary approach is derided by U.S. policy elites as a "mythical concept . . . like a unicorn."198 Yet if the analysis of the previous Section translates at all smoothly from the individual to the collective context, then the precautionary approach makes a great deal more concrete sense than PP critics appreciate: Even granting the causal optimizer's claim that "risks are on all sides of social situations,"199 that fact alone does not compel the adoption of an optimization standard, such as CBA, in which risks imposed and opportunities foregone are treated as analytically indistinguishable. Such a homogenized conception of the causal order threatens to undermine the basis on which moral agents have come to think of their actions as especially deserving of deliberation, choice, and responsibility. Put differently, no coherent conception of moral agency - even a collective one - can fully deny the distinctiveness of the agent's choices and actions in the manner compelled by impartial utilitarianism. Instead, something like the "first, do no harm" admonition of Hippocrates may be necessary at the collective level simply for the implicit reminder contained within it, that a political community's actions and decisions carry distinctive moral weight.

Of course, the desirable degree of agent-relativity for individual human actors does not necessarily supply the desirable de-

196. Cf. Frank Ackerman et al.,, Applying Cost-Benefit Analysis to Past Decisions: Was Protecting the Environment Ever a Good Idea?, 57 ADMIN. L.R. 155, 156 (2005).

197. Cf. SPASH, supra note 105, at 132.

198. McGarity, MTBE, supra note 23, at n. 323. John Graham, former head of the Office of Information and Regulatory Affairs for President George W. Bush's Office of Management and Budget, made the unicorn remark at a conference, organized in part by the European Commission, entitled "The US, Europe, Precaution and Risk Management: A Comparative Case Study Analysis of the Management of Risk in a Complex World." See http://www.whitehouse.gov/omb/inforeg/eu_speech.html (lasted visited Nov. 27, 2006).

199. Sunstein, Beyond the Precautionary Principle, supra note 13, at 1008. 
gree for collective actors. ${ }^{200}$ Most basically, the classic objections to fully impartial utilitarianism - that it disrupts a life filled with projects and meaning, ${ }^{201}$ or that it precludes special affiliations to family, friends, and colleagues ${ }^{202}$ — seem inapplicable to an institution that is charged, not with crafting an individual identity, but with serving the collective good of society. Indeed, one might argue that such institutions should be conceived and operated without any distinction between the effects of their policies, and the effects that are attributable to the larger causal system within which they operate. Institutional responsibility instead should include the fate of the entire system, unmediated by the "raft of baggage of personal attachments, commitments, principles and prejudices" that comprise an individual's narrative history. ${ }^{203}$

Practical considerations support this line of reasoning. Unlike individuals, who could never fulfill a duty of causal optimality with anything other than profound incompleteness, ${ }^{204} \mathrm{hu}$ man groups and institutions are thought to be able to more perfectly realize such a duty. Institutional actors can promulgate rules and distribute costs in a broad-sweeping manner that individuals in their private lives could not replicate. ${ }^{205}$ Also, as phi-

200. See Sunstein \& Vermeule, Capital Punishment, supra note 35, at 16 (noting that "[a] great deal of work has to be done to explain why 'inactive,' but causal, government decisions should not be part of the moral calculus"); Kelman, Taking Takings Seriously, supra note 184, at 1849-1851 (reviewing RICHARD A. EPSTEIN, TAKINGS: PRIVATE PROPERTY AND THE POWER OF EMINENT DOMAIN (1985)) (arguing that to translate individual rights and responsibilities uncritically to the collective sphere is to "reify like mad"); Forward, PUBLIC \& Private Morality (Stuart Hampshire, ed.) (1978) (collecting papers by Stuart Hampshire, T.M. Scanlon, Bernard Williams, Thomas Nagel, and Ronald Dworkin regarding "the dividing line between private life and public responsibilities").

201. See, e. g., George P. Fletcher, On the Moral Irrelevance of Bodily Movements, 142 U. PA. L. REV. 1443, 1451 (1994) ("There is nothing quite so unpredictable and insistent as having the circumstances determine when and how we must act."); Bernard Williams, $A$ Critique of Utilitarianism, in J.J.C. SMART \& BERNARD WILLIAMS, UTILITARIANISM FOR AND AGAINST 116-117 (1973) (arguing that utilitarian demands of "optimific decision" constitute "in the most literal sense, an attack on [one's] integrity," and the ability to stably and coherently pursue a life of one's own).

202. See SCHEFFLER, supra note 44, at 121 (arguing that "interpersonal relationships cannot play the fundamental role that they do in human life unless people treat their own relationships as independent sources of reasons for action."); HENRY HAZLITT, THE FOUNDATIONS OF MORALITY 193 (1964).

203. Robert E. Goodin, Utilitarianism as a Public Philosophy 9 (1995). ("It is the essence of public service as such that public servants should serve the public at large." Id.); Thomas Nagel, Ruthlessness in Public Life, in PUBLIC \& PRIVATE MoRaLITY, supra note 200 , at 75, 83 ("Public institutions are designed to serve purposes larger than those of particular individuals or families.”).

204. See SCHEFfler, supra note 44, at 43 (noting that "the individual agent qua individual agent typically will have only the most limited opportunities to influence . . global dynamics, and, indeed, cannot in general be assumed to have any but the sketchiest and most speculative notions about the specific global implications of his or her personal behavior.”).

205. See id. See also Kelman, Taking Takings Seriously, supra note 184, at 1851 (noting that states, as opposed to individuals, can more readily "state the scope of [positive] 
losopher Michael Green argues, "[i]nstitutions are better than individuals at collecting and processing information about the distant or indirect consequences of their actions." 206 Indeed, not only can institutional actors countenance a much greater spatial scope of concern than individuals, but they also can adopt a greater temporal scope of concern, given their legal immortality. ${ }^{207}$ For these reasons, one might well conclude that the criticisms traditionally lodged against utilitarianism for individuals fail to apply at the level of the nation-state and that, instead, an optimization rubric of the sort underlying CBA is desirable as a philosophy for government conduct. ${ }^{208}$

The metaethical points raised in the previous Section still remain, however, for some normative justification other than causal optimality is necessary to ground the conclusion that social actors should conform to an optimality standard. At bottom, the various arguments offered in favor of CBA reduce to statements that social actors and institutions can pursue causal optimality with fewer constraints and unintended side effects than individuals. Following Scheffler's argument on the individual level, however, it is not enough to say that social actors and institutions should optimize simply because it is the socially optimal thing to do. Not only is this statement sometimes empirically false, ${ }^{209}$ but it also is conceptually problematic in that it is incapable of explaining the embedded assumption that social institutions should do anything - that is, that the decisionmaking of such institutions should be the subject of norms of any sort. The reason for that assumption is that we implicitly recognize such institutions as "separate" moral agents, rather than simply as passive instruments of optimization. That is, even when we try to program our institutions to be "hostage to what the facts turn out to show in particular domains," 210 our very act of programming concedes the moral dis-

duties in administrable rule-like form" and utilize "a general system of taxation" to distribute the costs of fulfilling such duties in an equitable manner).

206. Michael J. Green, Institutional Responsibility for Global Problems 30 PHIL. ToPICS 79, 86 (2002), reprinted as Institutional Responsibility for Moral Problems, in GLOBAL RESPONSIBILITIES: SECURING RIGHTS BY DEFINING OBLIGATIONS 1117 (2005).

207. See GooDIN, supra note 203, at 129 (arguing that "public officials take a longer time horizon than do individuals planning their own private lives"); SCHEFFLER, supra note 44 , at 39 (noting that individuals "tend to experience . . . causal influence as inversely related to spatial and temporal distance").

208. See Goodin, supra note 203, at 27 (concluding that "[t]he same thing that makes [moral] excuses valid at the individual level - the same thing that relieves individuals of responsibility [from a duty of causal optimality] - makes it morally incumbent upon individuals to organize themselves into collective units that are capable of acting where they as isolated individuals are not"); Nagel, supra note 203, at 84 ("Within the appropriate limits, public decisions will be justifiably more consequentialist than private ones.”).

209. See supra text accompanying notes 93-95.

210. Sunstein \& Vermeule, Capital Punishment, supra note 35, at 30. 
tinctiveness of our institutional creations-and the possibility that they might be programmed according to other visions of societal flourishing.

Deep below the push for CBA therefore seems to lurk the same conception of collectivity that the methodology's proponents regard as suspect within the PP. For either approach to have compelling, persuasive, or even recognizable significance as a standard of social choice, it is necessary first to conceive of human institutions and societies as distinctive agents that can respond to reasons, articulate goals, and maintain self-awareness regarding the moral urgency of social policies. A necessary predicate for that conception, in turn, is to reject CBA's insistence that social choice can be reduced to a ministerial act of aggregation. Try as we might to deny it, the embrace of "Government house utilitarianism" is much more than a practical decision involving the institutional satisfaction of individual interests. It is a choice that reveals something intimate and foundational about our collective moral identity-something that will be lauded, lamented, or viewed indifferently by future generations, but that will always be seen as uniquely ours. As described in the next Section, unlike CBA, the PP embraces this fact of collective self-determination, and opens up space to meet the profound responsibilities contained within it.

\section{Moral Rationality}

Contrary to prominent critiques, the PP does not require us to embrace a fallacious belief that the larger causal fabric is benevolent ${ }^{211}$ or that human omissions are perfectly innocuous. ${ }^{212}$ Nor does it necessitate a return to the mistaken view that we can identify a stable "balance of nature" that exists beyond the influ-

211. Critics often believe that adherence to the PP suggests that individuals naively regard the status quo, the non-human, or the "normal" causal order as benign. See Sunstein, Beyond the Precautionary Principle, supra note 13, at 1009 (arguing that the "mistaken belief that nature is essentially benign ... often informs the precautionary principle"). Although most PP proponents harbor no such illusion, the more fundamental point is that some counterfactual baseline (such as the "normal" causal order absent one's actions) is necessary in order for any form of moral reasoning about human behavior to coherently proceed. See MOORE, infra note 212. After all, CBA has a baseline of its own, premised on a market liberal conception in which existing economic arrangements and preferences are given privileged status. See Kysar, Sustainable Development, supra note 41.

212. Michael Moore's contrary argument-that human omissions are "literally nothing at all"- seems just as difficult to sustain as the utilitarian notion that human actions are indistinguishable from other causal forces. MichaEL MOORE, ACT AND CRIME: THE PHILOSOPHY OF ACTION AND ITS IMPLICATIONS FOR CRIMINAL LAW 28 (1993). In both cases, the critical missing element is an appreciation for the role played by human choice and agency. See Fletcher, supra note 201, at 1444 (arguing that "the only kind of omitting that is interesting is the kind in which human agency is expressed"). 
ence of humans. ${ }^{213}$ Nor, finally, does the PP require that that we abandon the attempt to foster specific positive duties at the societal level (that is, institutional duties to act on the opportunity to prevent or alleviate suffering). The PP does, however, imply the view that human agents, whether individual or collective, bear moral responsibility in a way that other causal forces do not and, thus, that the decisionmaking of such agents should be conducted with a sense of moral urgency and self-awareness. Denying such a notion in favor of the fully impartial optimization rubric invites a slippery slope of instrumentalist decisionmaking in which moral boundaries are not only crossed routinely, but crossed without regret.

Some authors argue that a separate or distinct notion of collective agency in this manner "may not even be intelligible" and is, at least, of "obscure" moral relevance. ${ }^{214}$ This argument, while correct to the extent that it recognizes a larger scope of causal potential and moral obligation for the prevention of suffering by institutional actors, overshoots to the extent that it draws no distinction whatsoever between a political community and the larger causal order. After all, the same challenge that exists on the individual level-the challenge of pursuing morally desirable outcomes when the agent's causal potential both is filled with opportunities for acting and simultaneously is constrained by the omnipresence and power of other causal forces-also exists on the collective level. Even robust institutional actors such as nation-states confront a phalanx of forces that lie beyond complete prediction and control, such as the operations of natural systems that escape precise probabilistic understanding, the actions of foreign nations and other non-subjects that depend on and impact shared resources, ${ }^{215}$ and the future needs and circumstances of unborn generations

213. See A. Dan Tarlock, The Nonequilibrium Paradigm in Ecology and the Partial Unraveling of Environmental Law, 27 LOY. L. A. L. REV. 1121, 1122 (1994).

214. Sunstein \& Vermeule, Capital Punishment, supra note 35, at 6.

215. A single "risk monster" nation, for instance, may threaten unpalatable consequences for global environmental problems such as climate change, just as one "utility monster" threatens unpalatable consequences on the individual level. $C f$. ROBERT NOZICK, ANARCHY, STATE AND UTOPIA 110 (1974) (observing that "[u]tilitarian theory is embarrassed by the possibility of utility monsters who get enormously greater sums of utility from any sacrifice of others than these others lose"). In that respect, the fact that most of the industrialized world has pressed on with the Kyoto Protocol despite the overall tepidness of the document and the unwillingness of the United States to participate in the regime suggests that, to those nations, expected consequences do not fully determine the normativity of state action. Instead, the basis of climate policy in these nations seems to be a conviction that human societies and human generations owe each other certain moral responsibilitiesresponsibilities that must be discharged with care and caution in light of the deep uncertainty that accompanies global environmental disruption. 
that are a necessary but unknowable feature of any policy decision involving intergenerational consequences.

At times, the challenge of defining and performing a political role within this context becomes dramatically apparent. In the aftermath of Hurricane Katrina, for instance, one anonymous White House official initially sought to deflect criticism of the Bush Administration's response by arguing, "Normal people at home understand that it's not the president who's responsible for this, it's the hurricane."216 Four days later, with criticism mounting, President Bush embraced the opposite normative extreme, one in which the scope of the government's responsibility appeared to be co-extensive with the entire causal order: "[A]s long as any life is in danger, we've got work to do . . .." 217 As a statement of government responsibility for hurricane prevention and disaster relief, the latter quotation seems more desirable than the former quotation, which trades on a strong prescriptive version of the act-omission distinction that should be rejected. What both quotations share, however, is an acknowledgment of the state as an independently significant moral actor, one for which even an apparent duty of comprehensive lifesaving can only be imposed as a result of reasoning, choice, and responsibility.

The PP embraces the distinctiveness of collective decisionmaking. The political community that adopts and implements a precautionary approach does so with a recognition of itself as a member of a larger geopolitical and temporal community of communities. On this account, risk regulation is not merely an opportunity to maximize an existing set of individual welfare functions, but rather a moment to consider the regulating body's obligations to its present and future members, to other political communities, and perhaps even to other species. ${ }^{218}$ Such notions of decidedly col-

216. Scott Shane \& Eric Lipton, Government Saw Flood Risk But Not Levee Failure, N.Y. TIMES, Sept. 2, 2005 (quoting a White House official "who asked not to be named because he did not want to be seen as talking about the crisis in political terms").

217. George W. Bush, Address to Volunteers at Evacuee Shelter in Baton Rouge, Louisiana (Sept. 5, 2005), available at http://www.whitehouse.gov/news/releases/2005/09/ 20050905-9.html.

218. See, e.g., Christopher D. Stone, Should Trees Have Standing?--Toward Legal Rights for Natural Objects, 45 S. CAL. L. REV. 450 (1972) (arguing that law can, and should, view animals and other natural objects as having value and dignity in their own right). One continues to find supporters of Stone's position in the environmental law literature. See, e.g, Alyson C. Flournoy, In Search of an Environmental Ethic, 28 ColuM. J. ENVTL. L. 63 (2003) (arguing that environmental ethics should play a stronger role in environmental law and policy); Alyson C. Flournoy, Building an Environmental Ethic from the Ground Up, 37 U.C. DAVIS L. REV. 53 (2003) (supporting a transition away from exclusively humancentered utilitarianism as the foundation of environmental policy). However, William F. Baxter's classic work articulating the anthropocentric view, PEOPLE OR PENGUINS: THE CASE FOR OPTIMAL POLLUTION (1974), seems to have had the more dominant impact on 
lective responsibility are well demonstrated by the original German articulation of the $\mathrm{PP}$, Vorsorgeprinzip, which translates literally as "beforehand or prior care and worry" and which includes notions of "caring for or looking after, fretting or worrying about and obtaining provisions, or providing for." 219 Through these relational constructs, the $\mathrm{PP}$ offers a subtle, but constant reminder that the relevant political community's decisions express a collective identity - an identity that the community must in an important and unavoidable sense own. ${ }^{220}$

Rather than emerge from collective deliberation by a political community, policies adopted under the CBA approach instead are said to "inevitably and predictably" flow from the calculated effects of state action. ${ }^{221}$ Even assuming (unrealistically) that adequate knowledge is available to perform this ministerial conception of policymaking, it is unclear how CBA's results can retain authority over time, given that the framework implicitly denies the distinctiveness of its own audience. That is, rather than appearing within the CBA framework as responsive-and responsiblesubjects of moral reasoning, the individuals collectively comprising CBA's political community instead appear as simply part of the furniture of the optimization paradigm, the underlying normativity of which is likely to become increasingly obscure over time. The end result of such a conception may be a form of moral anesthetizing, ${ }^{222}$ one that occurs at precisely the moment when sensitivity and self-awareness regarding the deep uncertainty, complexity, and normativity of risk regulation are most in need.

This danger of moral anesthetizing seems to represent a problem not only for those who would invest CBA with foundational normative significance, but also for those who regard CBA simply as a decision procedure with practical worth in particular political settings. In Adler and Posner's view, for instance, CBA does not have "bedrock moral status," but instead serves only as a pragmatically useful mechanism for pursuing other values, such as overall well-being, that do have primary moral significance. ${ }^{223}$ The underlying conceptual

environmental law and scholarship. See Barton H. Thompson, Jr., People or Prairie Chickens: The Uncertain Search for Optimal Biodiversity, 51 STAN. L. REV. 1127, 1127-28 (1999).

219. S. Boehmer-Christiansen, The Precautionary Principle in Germany - Enabling Government, in INTERPRETING THE PRECAUTIONARY PRINCIPLE 34, 38 (Timothy O'Riordan \& James Cameron eds., 1994) (emphasis added).

220. Cf. Guido Calabresi, The Costs of Accidents: A Legal and Economic ANALYSIS 23 (1970) ("What we choose [in response to the problem of accidents], whether intentionally or by default, will reflect the economic and moral goals of our society."); CALABRESI \& BOBBIT, supra note 170, at 17 (noting that societies must inevitably choose who suffers and by how much and that "[i]n this way societies are defined").

221. Sunstein \& Vermeule, Capital Punishment, supra note 35, at 19.

222. I am grateful to Bill Eskridge for suggesting this phrase.

223. Adler \& Posner, supra note 15, at 195. 
problems raised by Gödel's Incompleteness Theroem, ${ }^{224}$ however, may haunt even those who defend CBA in this more pragmatic sense. The problem lies in the fact that the formal language of the cost-benefit framework is not only irreducibly incomplete; it also is capable of denying its own incompleteness. ${ }^{225}$ That is, even as CBA's moderate proponents depict the procedure as an aid to decisionmaking that is to be supplemented by other considerations, CBA implicitly and unavoidably condemns those other considerations as undesirable. Again, the tautological conclusion of the formalized welfarist framework is that subjectivity and fairness necessarily derograte from rationality and welfare. It is hard to see how such a framework can remain properly limited to its actual sphere of competency, as CBA's pragmatic defenders would have it, given that the framework offers the seductive possibility of translating all relevant variables into the language of optimization.

\section{CONCLUSION}

This Article has attempted to set out the underappreciated coherence and wisdom of the PP. Still, the problem remains that the PP by itself does not provide adequate substantive guidance as to how its various safety valves should be utilized. Nor does the principle tell us how to implement those safety valves in a manner that is consistent with the simultaneous demands of adaptive expertise and democratic legitimacy. Nor finally does the PP directly grapple with the profound intellectual and practical challenges of squaring a theory of intergenerational responsibility with liberal political theory. ${ }^{226}$ Development of such important issues will have to await further work. ${ }^{227}$ For now, it is enough to note that the task will require both humility regarding our powers of prediction and control, and courage regarding our ability to engage in a form of public decisionmaking that conceives of human societies and human generations as collective moral actors with their own agency, responsibility, and history.

The risks of oppression raised by such a collective vision are well known and justly feared. But the consequentialistutilitarianism of CBA has a less-recognized oppressive force of its own: By completely rejecting the distinctiveness of moral agency, CBA leads to a radical erasure of boundaries not only between in-

\footnotetext{
224. See supra text accompanying notes 118-119.

225. See supra text accompanying notes 194-195.

226. See Kysar, Sustainable Development, supra note 41.

227. See KYSAR, supra note 31.
} 
dividuals, but also between generations-a compressing of human history into a single moment of maximal net benefit, devoid of identities, relations, and responsibilities. As such, the optimization rubric invites an ethical counterpart to nanotechology's "gray goo" nightmare: a slippery universe of homogenized interests and influences in which the very distinctiveness of human identity and agency is slowly, but irretrievably erased. Put differently, the most basic normative message of the $\mathrm{PP}$, the Hippocratic adage, and other precautionary maxims - the reminder above all else to be moral ${ }^{228}$ — cannot be located within the optimization paradigm. To the contrary, the optimization paradigm works to render such a message unintelligible, for it erases the kinds of distinctions that enable us to identify moral agents to whom the reminder might be directed.

As this Article has argued, such a conception is incapable of long sustaining the notion that its results have compelling moral significance. Even complete acceptance of the causal optimality approach of CBA must depend on moral reasons for acceptance that find their source elsewhere than simply in a desire to optimize. Yet the political communities whose moral convictions supply this source hold no clear or secure place in the philosophy of optimization. Instead, the staunchly individualistic foundation of CBA denies political communities the capacity to collectively articulate their goals and ideals, a failing that seems especially problematic for policies impacting foreign nations, future generations, and other interest holders that are not already present in the optimization calculus. For such policies, a notion of collective agency provides the most analytically appropriate frame of evaluation, as it permits the political community to perceive itself as standing in relations of responsibility with, and historical connection to, those other political communities. Under CBA, on the other hand, those individuals whose lives are statistically, spatially, or temporally dispersed become subtly conscripted without their consent into a disembodied pursuit of utility-maximization. Indeed, under the optimization rubric, the "monetary equivalents" of their lives may be traded away for a few weeks' extension of the golf season. No amount of theorizing can make the sacrificed individuals "better off" in the bargain. 